\title{
Genomic signatures of globally enhanced gene duplicate accumulation in the megadiverse higher Diptera fueling intralocus sexual conflict resolution
}

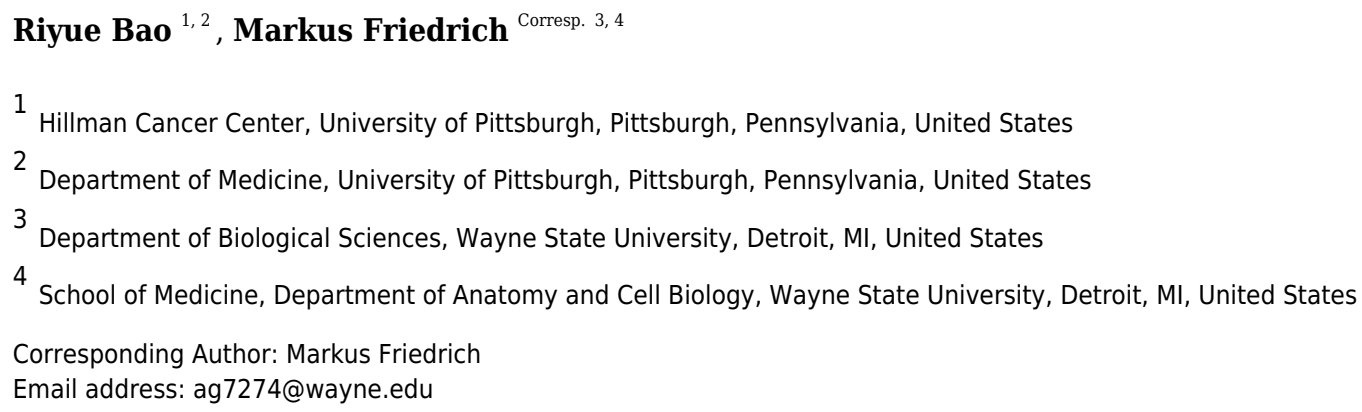

Gene duplication is an important source of evolutionary innovation. To explore the relative impact of gene duplication during the diversification of major insect model system lineages, we performed a comparative analysis of lineage-specific gene duplications in the fruit fly Drosophila melanogaster (Diptera: Brachycera), the mosquito Anopheles gambiae (Diptera: Culicomorpha), the red flour beetle Tribolium castaneum (Coleoptera), and the honeybee Apis mellifera (Hymenoptera). Focusing on close to 6,000 insect core gene families containing maximally six paralogs, we detected a conspicuously higher number of lineage-specific duplications in Drosophila (689) compared to Anopheles (315), Tribolium (386), and Apis (223). Based on analyses of sequence divergence, phylogenetic distribution, and gene ontology information, we present evidence that an increased background rate of gene duplicate accumulation played an exceptional role during the diversification of the higher Diptera (Brachycera), in part by providing enriched opportunities for intralocus sexual conflict resolution, which may have boosted speciation rates during the early radiation of the megadiverse brachyceran subclade Schizophora. 


\section{Genomic signatures of globally enhanced gene duplicate accumulation in the megadiverse higher Diptera fueling intralocus sexual conflict resolution}

Riyue Bao ${ }^{1,2}$ and Markus Friedrich ${ }^{3,4}$

1: Hillman Cancer Center, University of Pittsburgh Medical Center, Pittsburgh, PA

2: Department of Medicine, University of Pittsburgh, Pittsburgh, PA

3: Department of Biological Sciences, Wayne State University, 5047 Gullen Mall, Detroit, MI 48202

4: Department of Anatomy and Cell Biology, Wayne State University, School of Medicine, 540 East Canfield Avenue, Detroit, MI 48201

Author to whom editorial correspondence should be addressed:

Markus Friedrich, Department of Biological Sciences

Wayne State University 5047 Gullen Mall Detroit, MI 48202

Email: friedrichwsu@gmail.com phone: 3135779612 fax: 3135776891 


\section{ABSTRACT}

35 Gene duplication is an important source of evolutionary innovation. To explore the relative 36 impact of gene duplication during the diversification of major insect model system lineages, we 37 performed a comparative analysis of lineage-specific gene duplications in the fruit fly

38 Drosophila melanogaster (Diptera: Brachycera), the mosquito Anopheles gambiae (Diptera:

39 Culicomorpha), the red flour beetle Tribolium castaneum (Coleoptera), and the honeybee Apis

40 mellifera (Hymenoptera). Focusing on close to 6,000 insect core gene families containing

41 maximally six paralogs, we detected a conspicuously higher number of lineage-specific

42 duplications in Drosophila (689) compared to Anopheles (315), Tribolium (386), and Apis

43 (223). Based on analyses of sequence divergence, phylogenetic distribution, and gene ontology

44 information, we present evidence that an increased background rate of gene duplicate 45 accumulation played an exceptional role during the diversification of the higher Diptera

46 (Brachycera), in part by providing enriched opportunities for intralocus sexual conflict

47 resolution, which may have boosted speciation rates during the early radiation of the 48 megadiverse brachyceran subclade Schizophora. 
50

51

52

53

54

55

56

57

58

\section{Introduction}

150 years ago now, gene duplications became recognized as a major source of evolutionary innovation at the genetic level (Ohno, 1970). One hallmark validation of this conceptual advancement was the discovery of the Hox gene cluster, the deeply conserved string of tandem-duplicated transcription factor genes, which regulate the patterning of the longitudinal animal body axis (Lewis, 1992; Carroll, 1995; Ryan et al., 2007; He et al., 2018). Today, genome sequencing studies continue to uncover adaptive gene family expansions facilitated by gene duplication, which have affected a wide range of phenotype dimensions such as body plan innovation (Cañestro, Yokoi \& Postlethwait, 2007; Holland et al., 2017; Sakuma et al., 2019), sensory reception (Smadja et al., 2009), sexual reproduction (Connallon \& Clark, 2011), or diet range (Zhao et al., 2015; Pajic et al., 2019), to list a few. The availability of whole genome sequences has made it also possible to quantify the global impact of gene duplication on the genetic evolution of organismal lineages. The first comprehensive study in this direction revealed that gene duplications occur at a frequency of close to 0.01 per gene per million years (Lynch \& Conery, 2000), thus ranking equivalent with other mutational mechanisms in generating genetic variation in natural populations. The same work confirmed the expectation that most newly born gene duplicates experience rapid decay into pseudogenes. Recent studies, however, also produced evidence for a generic advantage of nascent gene duplicates in buffering gene expression noise (Rodrigo \& Fares, 2018). Notwithstanding the nature of forces acting upon new gene duplicates, the opposing effects of gene duplication and loss events have been found to lead to rapid rates of gene turnover, which can translate into dynamic gene family size evolution(Hahn, Han \& Han, 2007). There is, however, also a long trail of gene duplicates, which become long-term preserved due to either the complementary partitioning of ancestral pleiotropy (subfunctionalization) between sister paralogous gene duplicates or the acquisition of novel functions (neofunctionalization) by one of them (Force et al., 1999; Innan \& Kondrashov, 2010). In addition, also benefits arising from genetic redundancy such as the suppression of regulatory noise can lead to hundreds of millions of years of conservation of overlapping ancestral functions in duplicated genes (Conant and Wagner, 2004, Gu et al., 2003, Hanada et al., 2009, Hsiao and Vitkup, 2008, Tischler et al., 2006, Vavouri et al., 2008; Friedrich, 2017). 
80 mechanisms that lead to gene duplicate fixation and long-term conservation. Also the diversity,

81 frequencies, and adaptive significance of gene duplication outcomes remain an area of

82 continued progress in comparative genomics. In this context, it is the dichotomy of conservative

83 or neutral vs innovative gene duplication outcomes, such as sub- vs neofunctionalization, which

84 remains of fundamental interest in molecular evolution (van Hoof, 2005; Dean et al., 2008;

85 Kondrashov, 2012; Qian \& Zhang, 2014; Wang et al., 2016; Lan et al., 2016; Holland et al.,

86 2017; MacKintosh and Ferrier 2017; Marlétaz et al., 2018; Sandve et al., 2018).

87

88

89

90

91

92

93

94

95

96

97

98

99

100

101

102

103

104

105

106

107

108

109

110

Arguably the most dramatic examples of how gene duplications provided the genetic substrate for expansions of organismal complexity and diversification are the gene duplicate enriched genomes of angiosperms in plants and vertebrates in animals, both of which date back to several rounds of whole genome duplications (Jiao et al., 2011; Cañestro et al., 2013). A whole genome duplication has also been discovered at the base of the highly diversified arthropod subphylum Chelicerata followed by additional whole genome duplications in younger clades of this group (Schwager et al., 2017; Nong et al. 2020). At the same time, current data do not speak for an obligatory connection between gene duplication and taxonomic diversification. With close to 1 million documented species, insects stand at the forefront of understanding the origins of organismal diversity (Labandeira \& Sepkoski, 1993; Grimaldi \& Engel, 2005). However, comparative genomic evidence now solidly rules out that whole genome duplications preceded the unparalleled expansion of this group. Seeded by the Drosophila genome project (Myers et al., 2000), the genomic exploration of insect diversity has amounted to over 100 sequenced genomes within the last 15 years (Yin et al., 2016). This progress is the result of targeted efforts such as i5k initiative, which strives for the completion of 5,000 high-priority arthropod genomes (i5K Consortium, 2013). The analysis of the first 28 genomes resulting from this effort together with 48 additional arthropod genomes suggests that gene duplicate accumulation rates remained remarkably steady over the about 450 million years of insect evolution (Thomas et al., 2020). The preceding analysis of the gene content in genome or transcriptome data sets of over 150 species representing all 41 insect orders, in contrast, reported evidence of substantial fluctuations in gene duplicate contents in over 15 insect orders (Li et al., 2018). While the strength of evidence for whole genome duplications has been refuted (Nakatani \& McLysaght, 2019; Roelofs et al. 2020), these findings still leave room for the possibility that dramatically enhanced local gene duplicate retention rates played important roles 
111 in the exceptional diversification of insects.

112 Further noteworthy in this respect is that fact that the first reported insect genome with a

113 dramatically higher number of lineage-specific gene duplications (close to 2,500), that of the

114 pea aphid Acyrthosiphon pisum (International Aphid Genomics Consortium, 2010; Julca et al.

115 2020), failed to be detected in the recent study mentioned above ( $\mathrm{Li}$ et al., 2018). This suggests

116 that continued efforts are likely to refine our understanding of important gene family content

117 changes in insect evolution. Studying the evolutionary histories of vision-related genes in insect

118 genome models, we previously noted an unusually high number of duplicated genes in

119 Drosophila melanogaster (Bao \& Friedrich, 2009). In a followup study of over 350

120 developmental gene families, we discovered a preponderance of ancient, yet lineage-specific

121 gene duplicates in Drosophila and the higher Diptera (Brachycera) (Bao et al., 2018). Moreover,

122 more than $50 \%$ of these lineage-specific developmental gene duplications retained partial or

123 complete genetic redundancy despite their ancient separation. This led us to hypothesize that the

124 exceptional accumulation of developmental gene duplicates in Drosophila and the higher

125 Diptera was of adaptive nature by increasing genetic robustness as a requirement for the fast

126 development of brachyceran Diptera such as Drosophila. At the same time, the similarly higher

127 number of structural vision genes gave reason to suspect the possibility of a genome-wide

128 increase of gene duplicate accumulation in the higher Diptera (Bao \& Friedrich, 2009; Bao et

129 al., 2018).

130 As global studies of insect gene family contents did not produce evidence of an overall

131 higher gene content in Drosophila vs non-dipteran insects (Honeybee Genome Sequencing

132 Consortium, 2006; Richards et al., 2008; Thomas et al., 2020), we compared the numbers of

133 lineage-specific gene duplicates in insect core gene families of small to moderate size $(<6$

134 paralogs). This approach was meant to eliminate the effect of adaptive gene family expansions

135 in order to quantify the relative amounts of gene duplicate accumulation resulting from the

136 average background rate of physical gene duplication events followed by successful fixation

137 and longterm conservation. As a first step in this direction, we analyzed the gene contents of

138 three distantly related, well-curated holometabolous insect genome species in comparison to $D$.

139 melanogaster. The results from this four species comparison indicate that the megadiverse

140 dipteran infraorder Brachycera is characterized by a genome-wide higher rate of gene duplicate

141 accumulation. Gene ontology analysis, however, further indicates that energy metabolism genes 
142 were exceptionally affected by this trend during the diversification of schizophoran Diptera, i.e.

143 the most recent of three major radiations in this insect order, between 40-60 million years ago

144 (Wiegmann et al. 2011). Almost invariably, these lineage-specific energy metabolism gene

145 duplications spawned germline-specific paralogs thereby resolving conflicting selection

146 pressures on their ancestral singleton loci. Given the theoretical and empirical evidence that the

147 emergence of germline-specific gene duplicates enforces species barriers, our findings point to a

148 potentially important link between gene duplication and speciation rates in the higher Diptera in

149 addition to documenting a higher global gene duplicate accumulation rate in this clade.

150

151 METHODS AND MATERIALS

152

153 Genome and sequence datasets

154 The genome assemblies used in this study were Drosophila melanogaster genome 155 assembly 5.3 (Myers et al., 2000), Mayetiola destructor genome assembly 1.0 (Zhao et al., 156 2015), Anopheles gambiae str. PEST genome database version 3.0 (Sharakhova et al., 2007), 157 Tribolium castaneum Georgia GA2 genome database version 3.0 (Richards et al., 2008), and 158 Apis mellifera DH4 genome database version 4.0 (Honeybee Genome Sequencing Consortium, 159 2006). The protein databases used in this study were GenBank RefSeq protein databases of $D$. 160 melanogaster, A. gambiae, T. castaneum, and A. mellifera (Pruitt, Tatusova \& Maglott, 2005) 161 and Official gene set (OGS) protein databases of M. destructor (version 1.0) (Zhao et al., 2015), 162 T. castaneum (version 1.0) (Richards et al., 2008), and A. mellifera (version 2.0) (Honeybee

163 Genome Sequencing Consortium, 2006). The NCBI RefSeq and OGS protein sequence 164 databases of T. castaneum and A. mellifera each were merged to create more comprehensive 165 protein datasets. Four-way pairwise BLASTP searches were performed between the protein 166 databases of D. melanogaster, A. gambiae, T. castaneum, and A. mellifera. M. destructor 167 homologs were retrieved by searching D. melanogaster query proteins against $M$. destructor 168 OGS protein database. In addition, $A$. gambiae genome sequences were downloaded from the 169 GenBank RefSeq nucleotide database (Pruitt, Tatusova \& Maglott, 2005) and searched against 170 using D. melanogaster proteins as the query by TBLASTN (Altschul et al., 1990) to retrieve 171 possible mosquito homologs not annotated in its RefSeq protein database. Additional genome 
172 databases interrogated in the analysis of the brachyceran enriched metabolism genes included

173 that of the Mediterranean fruit fly Ceratitis capitata (Papanicolaou et al., 2016), the stalk-eyed

174 fly Teleopsis dalmanni (Vicoso \& Bachtrog, 2015), the calyptrate Diptera Musca domestica

175 (common house fly) (Scott et al., 2014) and Glossina morsitans (tsetse fly) (International

176 Glossina Genome Initiative, 2014), the onion fly Delia antiqua (Zhang et al., 2014), the robber

177 fly species Proctacanthus coquilletti (Dikow et al. 2017), the bibionomorph species Contarinia

178 nasturtii (swede midge) (GenBank assembly GCA_009176525.2) and Sitodiplosis mosellana

179 (orange wheat blossom midge) (GenBank assembly GCA_009176505.1), the mosquito species

180 Aedes aegypti (yellow fever mosquito) (Nene et al., 2007) and Culex quinquefasciatus

181 (mosquito species) (Pelletier \& Leal, 2009), and the sand fly species Lutzomyia longipalpis

182 (GCA_000265325.1) and Phlebotomus papatasi (GCA_000262795.1).

183

184

Duplicate detection and classification pipeline

The duplication detection and classification was conducted by adopting the pipeline developed in our previous analysis of developmental gene duplicates (Bao et al., 2018). In short, species-specific protein databases (RefSeq and OGS when available) were downloaded from GenBank or respective genome project websites. For each species, databases from different sources were merged based on identical associated GeneID suggested by the Gbrowser to obtain a final protein database void of no redundant sequences. Inter- and intra-species BLAST searches were performed with protein sequences of each species as queries against the database of itself or from the other species, with E-value cutoff set as 1.0 $\mathrm{e}^{-4}$ (Altschul et al., 1990).

Next, gene families were sorted into three classes, 1) 1:1

orthology if the gene had 1:1 orthologs in at least two additional species, 2) ancient duplication if it resulted from a duplication that

196 happened before the insect diversification, 3) lineage-specific duplication if this gene has independent duplication(s) occurred in any of the four species. This classification was achieved in two steps. In the first step, ortholog numbers for a given gene family of each species were determined by the following logic. Assuming there 
are $a, b, c$, and d numbers of orthologs corresponding to 1 query gene in each of the four species, $a=b=c \geq d$ defined $1: 1$ orthology if each $a, b$, and $\mathrm{c}$ equaled $\mathrm{l}$ and as ancient duplication if $\mathrm{a}, \mathrm{b}$, and $\mathrm{c}$ were larger than 1 . The condition $a>b=c \geq d$, by contrast, defined a family associated lineage-specific duplication in the species with more than one ortholog. The approximately 10\% of gene families that did not fall into any of the three categories above were classified as unresolved groups and further analyzed in the second part of the classification analysis, which involved manual assignment of duplication labels to each gene family based on gene tree analysis results.

Gene family validation

213 In order to compare the validation data from our previous analysis of a manually curated 214 subset of 377 validation gene families (Drăghici, 2011; Bao et al., 2018) with the genome-wide 215 duplication identification output (Supplementary data file 2), every individual gene in the two 216 data sets was assigned with a with a 6-digit code, which reflected its inferred gene duplication

217 history. Genes with 1:1 orthologs in all four lineages were assigned with the code 100000.

218 Genes associated with duplication events that were shared by two or three lineages were 219 assigned with code 010000. Code positions 3-6 indicated lineage-specific duplication events in 220 one of the four lineages. As an example, code variant 001010 represented a gene that had independently duplicated in the lineages to Drosophila and Tribolium. In the next step, genes present in both datasets were compared directly based on their assigned duplication labels and classified into four comparison results based on each position of the 6 digits: 1) False positive, if

224 the gene appeared negative in the validation dataset but positive in the genome-wide analysis; 2 )

225 False negative for genes that were positive in the validation dataset but negative in the study; 3 ) 226 True positive for genes that were positive in both results; 4) True negative for genes associated 227 with negative codes in both datasets. Each gene was calculated redundantly in each position of 228 the six digits, meaning that if one gene was positive for 1:1 orthology, it was counted as zero for 229 the other five positions. 


\section{Calculation of $d S$ values}

232 Protein sequences of duplicated genes were aligned with ClustalW2 (Larkin et al., 2007)

233 and the corresponding cDNA alignments were generated by PAL2NAL version 13 (Suyama,

234 Torrents \& Bork, 2006) using the aligned protein sequences as input. Ambiguously aligned

235 regions were removed by Gblocks 0.91b (Talavera \& Castresana, 2007) with the block

236 parameter "Allowed gap positions" set to "None". The gap-filtered cDNA alignments were used

237 to calculate synonymous substitution divergence values (dS) with the yn00 algorithm of PAML

238 version 4.4 (Yang, 2007). In the case of multiple duplications within the same gene family, dS

239 values were determined for all paralog combinations and the smallest and largest values were

240 selected for the analysis of gene duplicate age distribution.

241

242

Phylogenetic tree reconstruction

243 For the genome-wide survey, ClustalW2 (Larkin et al., 2007) was used to generate the

244 multiple sequence alignments, which were subsequently purged of ambiguously aligned sites

245 and divergent regions Gblocks (Castresana, 2000) applying least stringency settings, before

246 neighbor gene gene tree reconstruction with JTT protein substitution model distances executed

247 in Phylip package version 3.69 on Wayne State Grid supercomputing cluster (Saitou \& Nei,

248 1987; Whelan \& Goldman, 2001; Felsenstein, 2005). Specifically, the Seqboot module created

249100 bootstrap replicates from the protein alignment input, followed by "Protdist" calculation of

250 protein distance matrices for each bootstrap dataset applying JTT model, followed by neighbor

251 joining tree generation for each dataset with the "Neighbor" module, and consensus tree

252 calculation through the "Consense" module.

253 For the expanded analyses of gene family evolution, we collected homologs via

254 reciprocal BLAST in the species-specific protein sequence, whole genome sequence, and TSA

255 databases at NCBI. Gene trees were estimated with RAxML as implemented in the CIPRES

256 Science Gateway environment from multiple protein sequence alignments generated with

257 Clustal followed by ambiguous site removal with Gblocks at least stringent settings (Miller,

258 Pfeiffer \& Schwartz, 2010; Sievers et al., 2011; Stamatakis, 2014). Tree rendering and

259 annotation was conducted in the iTOL environment (Letunic \& Bork, 2016). 
261 Gene Ontology analysis

262 The distribution of functional categories associated with lineage-specific duplication

263 gene sets was evaluated by analysis of Gene Ontology (GO) terms (Ashburner et al., 2000)

264 using the BiNGO tool (Maere, Heymans \& Kuiper, 2005) from Cytoscape package v. 2.8

265 (Smoot et al., 2011) with customized settings: study set and reference set as listed in

266 (Supplementary data file 5), annotation file as the FlyBase version downloaded from Gene

267 Ontology official website (http://www.geneontology.org/GO.downloads.annotations.shtml,

268 updated 08/04/2011), and ontology file as OBO version 2.0 downloaded from Gene Ontology

269 official website (http://www.geneontology.org/GO.downloads.ontology.shtml, updated

270 08/04/2011), with namespace chosen as Biological Process. The statistical test was set to

271 hypergeometric test, and multiple testing correction set to Benjamini \& Hochberg False

272 Discovery Rate (FDR) correction (Benjamini \& Hochberg, 1995). The significance level was

273 chosen as 0.05 . GO annotations of non-Drosophila genes were assigned based on their

274 orthologs in Drosophila. Afterwards, representative GO terms were detected and visualized by

275 removing redundant GO terms using REViGO (Supek et al., 2011) with the list of significant

276 GO terms with their associated FDR corrected p-values as the input, the resulting list set to

277 small (cutoff clustering score $=0.5$ ), the database with GO term sizes set as Drosophila

278 melanogaster UniProt (McGarvey et al., 2019) and the semantic similarity measure method set

279 as SimRel (Schlicker et al., 2006).

280

281 Results

282

283

Drosophila is two-fold richer in duplicated insect core genes compared to mosquito, flour

284 beetle, and honeybee

285

To probe for a genome-wide increase in gene duplicate accumulation in the lineage

286

leading to Drosophila, we compared the gene family content of D. melanogaster with three

287 additional insect genome model species: the mosquito Anopheles gambiae (Diptera:

288 Culicomorpha), the red flour beetle Tribolium castaneum (Coleoptera), and the honeybee Apis mellifera (Hymenoptera). To normalize the data sets, we excluded species-specific orphan gene 
290 families and restricted the analysis to gene families that were conserved in at least three of the

291 four species. To compare base rates of gene duplicate accumulation, we excluded gene families

292 with more than six members to eliminate the effect of massively adaptive gene family

293 expansions. In combination, these criteria narrowed the comparison to 5,983 insect core gene

294 families conserved in Drosophila. Of these, 5,581, 5,505, and 5,448 were recovered in mosquito, 295 red flour beetle, and the honeybee, respectively (Supplementary data file 1).

296 Lineage-specific gene family expansions were inferred via a previously described

297 bioinformatic pipeline involving sequence similarity threshold filtering, reciprocal BLAST tests, 298 and, in a subset of cases, gene tree reconstruction (Bao et al., 2018). Running a comparison to 299 our previously manually curated sample of 377 developmental gene families for validation 300 analysis (Drăghici, 2011; Bao et al., 2018), we obtained evidence of 90\% or better accuracy 301 (percentage of true positives) and $85 \%$ or better specificity (percentage of true negatives) for 302 our automated gene family analysis pipeline (Supplementary data file 2).

303

In total, our bioinformatic approach detected 1,211 gene families with high confidence

304 lineage-specific gene duplications (Supplementary data file 1). 190 of these were characterized

305 by independent gene duplication events in more than one of the four lineages. At the species

306 level, we found 698 gene families with lineage-specific duplications in Drosophila, 315 in

307 Anopheles, 386 in Tribolium, and 223 in Apis (Fig. 1). Normalized for the species differences in

308 homolog contents, $11.7 \%$ of insect core gene families were identified as expanded via lineage-

309 specific gene duplications in the Drosophila lineage, which compared to 5.6\%, 6.7\%, and 4.1\%

310 in Anopheles, Tribolium, and Apis, respectively (Table 1). This on average 2-fold higher number

311 of lineage-specific gene family expansions in Drosophila was consistently reflected in the large

312 category of post-duplication 2-members large gene families and even more strongly in the gene

313 families with 3 up to 6 extant paralogs (Table 1). Falling notably in line with the previously

314 detected two times higher number of developmental gene duplications in the Drosophila lineage

315 in the same comparative framework (Bao et al., 2018), these findings supported a genome-wide

316 increase in gene duplicate accumulation as explanation for the previously detected higher

317 numbers of both vision and developmental gene duplications in Drosophila vs Anopheles,

318 Tribolium, and Apis ( (Bao and Friedrich 2009; Bao et al., 2018). 


\section{The majority of the Drosophila-lineage gene duplicates are old}

321

322

323

324

325

326

327

328

329

330

331

332

333

334

335

336

337

338

339

340

341

342

343

344

345

346

347

348

349

To gain insight into the time dimensions of insect core gene duplicate accumulation in the four insect lineages, we surveyed the synonymous substitution differences (dS) between gene family paralogs as proxies of gene duplicate ages (Supplementary data file 3 ). The majority of the duplicate pairs in all four lineages were associated with dS values higher than 2.0, indicative of relatively ancient origins (Fig. 1). This trend was most pronounced in the Drosophila lineage where $92.2 \%$ of the gene duplicate pairs were characterized by dS values higher than 2.0 compared to $82.7 \%, 87.9 \%$, and 88.2\% in Anopheles, Tribolium, and Apis, respectively.

While straightforward to compute, $\mathrm{dS}$ values are coarse estimates of evolutionary time dimensions, especially in the case of short gene sequences due to sample size errors. We therefore also probed for the conservation of the Drosophila lineage-specific gene duplications in the genome of the Hessian fly Mayetiola destructor (Zhao et al., 2015). This pest species is a representative of the dipteran infraorder Bibionomorpha, the now well established sister clade of the Brachycera (Wiegmann et al., 2011). Thus, duplications shared by $M$. destructor and $D$. melanogaster to the exclusion of $A$. gambiae would be diagnosed to be of pre-Brachyceran origin, while duplications unique to D. melanogaster to the exclusion of both M. destructor and A. gambiae, were more likely to have occurred at a later time point, i.e. during the diversification of brachyceran flies.

Reciprocal BLAST searches recovered 385 (55.1\%) of the 698 gene families with Drosophila-lineage specific duplications in M. destructor (Supplementary data file 4). 75 (18.5\%) of these shared two or more 1:1 orthologs in the Hessian fly, implying a prebrachyceran origin. For the remaining 185 gene families, we only detected singleton orthologs in the Hessian fly genome, characterizing them as Brachycera-specific. Thus taken together, interparalog dS divergences and gene duplicate conservation in the Hessian fly suggested that only about $20 \%$ of the close to 700 Drosophila-specific insect core gene duplications detected in our initial four-species comparison had accumulated before the split of the last ancestor of Hessian fly and Drosophila, while the majority originated later, during the expansion of the megadiverse Brachycera. 


\section{Enrichment of energy metabolism functions in the Brachycera-specific gene duplicates}

To gain insights into possible phenotypic corollaries of the heightened number of duplicated insect core genes in brachyceran Diptera, we tested for enrichment of biological processes (BP) using gene ontology (GO) analysis tools (Ashburner et al., 2000; Dennis et al., 2003; The Gene Ontology Consortium, 2015). We were able to apply this approach to 1403 , 841, 860, and 426 gene duplicates of Drosophila, Anopheles, Tribolium, and Apis, respectively, based on the BP information available in FlyBase at the time of the analysis (Drysdale et al., 2005).

Biologically meaningful GO term enrichment signals indicated informativeness of the approach (Fig. 2 and Supplementary data file 5). The GO-term 'chitin metabolic processes' (GO:0006030), for instance, was exclusively enriched in the gene duplications specific to the Tribolium-lineage, consistent with previously reported expansions of chitin metabolism gene families in the Coleoptera (Arakane et al., 2005; Dixit et al., 2008) and the generally chitinenriched cuticle of darkling beetles (Tenebrionidae) like Tribolium (Finke, 2007). Furthermore, the GO terms 'generation of precursor metabolites and energy' (GO:0006091) and 'cellular carbohydrate metabolic process' (GO:0044262) were significantly enriched in all species except Anopheles (Fig. 2A and Supplementary data file 5). This genomic signal boded well with the fact that mosquitoes, in many cases, subsist on a carbohydrate-poor diet of vertebrate blood and plant pollen in contrast to the generally carbohydrate-rich diets in the clades represented by Drosophila, Apis, and Tribolium (Foster, 1995).

Interestingly, the population of Drosophila-lineage gene duplicates was characterized by the lowest number of enriched BP GO-terms (43) but the highest number of underrepresented BP GO-terms (206) (Fig. 2 and Supplementary data 5). even more remarkably, the latter category included many developmental GO terms (Fig. 2 and Supplementary data 5), despite our previous finding that Drosophila possesses a two-fold higher number of duplicated developmental genes compared to Anopheles, Tribolium, and Apis (Bao et al., 2018). However, developmental GO terms were generally underrepresented in the lineage-specific gene duplications (Fig. 2), consistent with evidence that developmental gene regulatory networks are generally less tolerant to gene duplication (Davidson and Erwin, 2006).

In the Drosophila population of lineage-specific gene duplicates, significantly enriched 
380 BP GO-terms were predominantly related to energy metabolism (Fig. 2, Supplementary data 5).

381 Given the distinct structural and physiological features of brachyceran Diptera (Wiegmann et

382 al., 2011), we also analyzed BP GO-term enrichment separately for the subsets of 234 pre-

383 brachyceran vs 1167 identified Brachycera-specific gene duplications. This approach detected

38439 significantly enriched GO terms in the population of Brachycera-specific gene duplications

385 all of which were related to energy metabolism. The 25 significantly enriched BP GO-terms in

386 the population of pre-brachyceran gene duplications, in contrast, represented different

387 categories of biological function (Fig. 2) (Supplementary data file 5).

388

389

Schizophora-concentrated origins of the Drosophila lineage energy metabolism-related gene duplicates

391

392

To explore the biological significance of energy metabolism-related gene duplications in

393

brachyceran flies, we focused on gene duplicates in BP GO term categories that were

394 significantly enriched in the Brachycera-specific gene duplications but not in any of the other investigated lineages (Supplementary data 5). This condition was met for the BP GO terms 'cell redox homeostasis' (GO:0045454), 'protein targeting to mitochondrion’ (GO:0006626), 'protein localization in mitochondrion' (GO:0070585), 'establishment of protein localization in mitochondrion' (GO:0072655), ‘carbohydrate phosphorylation' (GO:0046835), ‘dicarboxylic acid metabolic process' (GO:0043648), and ‘polyol metabolic process' (GO:0019751). Combined, these gene function populations constituted 189 Drosophila genes in 111 gene families of which, based on our initial pipeline results, 17 gene families had expanded due to Brachycera-specific gene duplications.

To scrutinize the predicted absence of these duplications outside Brachycera, we searched the genomes of additional mosquito (Suborder Culicomorpha), sandfly (Suborder Psychodomorpha), and gall midge (Suborder Bibionomorpha) species for homologs (Fig. 3). Most sampled gene families were only represented by singleton orthologs in these nonbrachyceran species (Supplementary file data 6). In two cases, however, i.e. the Thioredoxin and Malic enzyme gene families, the manual homolog search raised the initial gene family count from one to two with separate orthologs in the non-dipteran outgroups (Supplementary data 6). 
410 Both of the Malic enzyme gene subfamilies contained Drosophila-lineage duplicates, thus

411 increasing the number of de facto investigated gene family expansions to 18 .

412 Only one duplication event mapped outside Brachycera to the last common ancestor 413 (LCA) of Brachycera and Bibionomorpha (see below) (Supplementary data file 6). Overall, the 414 manual homolog conservation analysis confirmed the Brachycera-specificity of the energy415 metabolism related gene duplications.

416 To explore the taxonomic depths of the metabolic gene duplications within brachyceran 417 Diptera, we searched for homologs in a broader sample of schizophoran Diptera (Fig. 3 and 418 Supplementary data file 6). Moreover, to differentiate between gene duplicates that dated back 419 to the stem lineage of brachyceran Diptera vs duplicates that originated subsequently during 420 brachyceran diversification, we searched the high coverage genome of the assassin or robber fly 421 species Proctacanthus coquilletti as a representative of orthorrhaphan Brachycera (Fig. 3 and 422 Supplementary data file 6) (Dikow et al. 2017).

423 Mapping the taxonomic distribution of gene duplicate conservation on this sampled 424 framework of bachyceran phylogeny (Bao et al., 2018), we found that the majority of the energy 425 metabolism-related gene duplications in the lineage to Drosophila, i.e. 21 out of 32 (66\%), 426 originated in the lineage from the LCA of calyptrate + drosophilid Diptera to that of drosophilid 427 Diptera (D. melanogaster and D. virilis) (Fig. 3). In addition, five further duplications mapped 428 into the schizophoran clade of brachyceran Diptera: Three to the terminal branch of $D$. 429 melanogaster representing the Sophophora subgroup of drosophilid Diptera and two back 430 deeper to the lineage from the LCA of schizophoran Diptera to the LCA of calyptrate + 431 drosophilid Diptera (Fig. 3).

432 Five duplications, finally, preceded the radiation of schizophoran Diptera (Fig. 3 and 433 Supplementary data 6). Three of these stemmed from duplication events in a single gene family, 434 generating the four Thioredoxin gene family paralogs of $D$. melanogaster that mapped to the 435 relatively long, taxonomically still undersampled branch linking the LCAs of schizophoran and 436 brachyceran Diptera (see below and Supplementary data file 6). Only one duplication mapped 437 outside Brachycera to the LCA of Brachycera and their sister clade, the Bibionomorpha (see 438 below, Fig. 3 and Supplementary data 6). Overall, the taxonomic distribution of gene duplicate 439 conservation was in line with the general ancientness of the Brachycera-specific gene 
440 duplications indicated by the interparalog dS divergences (Fig. 1) but also revealed the mostly

441 schizophoran origins of the analyzed $D$. melanogaster energy metabolism gene duplicates.

442

443 Increased duplication accumulation rate in the energy metabolism gene population during 444 schizophoran diversification

445 The concentration of energy metabolism gene duplications in the schizophoran lineage

446 to the LCA of Drosophilidae differed from the previously reported, more evenly distributed

447 accumulation of developmental gene duplications in brachyceran Diptera. Specifically, close to

$44885 \%$ of the duplications in energy metabolism-related gene families mapped into the

449 schizophoran clade of dipteran phylogeny (Fig. 3) in contrast to close to $55 \%$ of developmental

450 gene duplications (Bao et al. 2018). One difference between the current analysis and the

451 previous study of developmental gene duplications was the inclusion of the robber fly $P$.

452 coquilletti to differentiate between gene duplicates that originated in the stem lineage of

453 brachyceran Diptera vs the lineage preceding the diversification of schizophoran species (Bao et

454 al., 2018). To make the data sets more comparable, we therefore explored the conservation of 31

455 duplications in 25 developmental gene families that we had previously determined to have

456 originated prior to the diversification of schizophoran Diptera. This was accomplished by

457 probing for evidence of homolog conservation in the robber fly $P$. coquilletti. In addition, we

458 scrutinized for the Brachycera-specificity of these duplications by searching for homologs in the

459 gall midge C. nasturtii (Supplementary data file 7) (Fig. 3). This effort mapped 18 duplications

460 to the lineage from the LCA of brachyceran Diptera to that of Schizophora, while eight

461 duplications mapped to the brachyceran stem lineage and three to the even older LCA of

462 Bibionomorpha and Brachycera (Supplementary data file 7).

463 Normalizing the proportions of gene duplicates per total numbers of gene families

464 sampled in the developmental and energy-related gene populations, i.e. 377 vs 111 respectively,

465 we generated estimates of duplicate accumulation rates in the two gene populations along the

466 brachyceran lineages leading to Drosophila (Table 2). Along most branches, the accumulation

467 rates appeared similar, not exceeding 2 -fold differences and averaging 0.0016 vs 0.001

468 duplications per gene family per million years for energy metabolism vs developmental genes,

469 respectively. Moreover, both gene populations were characterized by a 4-fold increase in gene 
470 duplicate accumulation rate in the lineage from the LCA of schizophoran Diptera to that of 471 Drosophilidae and calyptrate Diptera (Table 2). Most notable, however, in the schizophoran 472 lineage connecting the LCA of Drosophilidae+Calyptratae to that of Drosophilidae the gene 473 duplicate accumulation rate in the energy metabolism gene population peaked even further to 4740.0054 , exceeding that of the developmental gene population (0.0011) by a factor of 5 (Table 2 ).

475 These findings suggested that duplications accumulated at higher rate during early schizophoran 476 evolution in both gene populations except for an additional spike in the energy metabolism 477 population in the schizophoran lineage to Drosophilidae.

478

Pervasive germline subfunctionalization in the enriched energy metabolism-related gene duplicate population

To gain insights into the biological significance of the energy metabolism-related gene duplications, we mined D. melanogaster gene expression data available through the modENCODE database (Chen et al., 2014). This effort revealed that all of the 18 energy metabolism-related gene families included germline-specific paralogs (Table 3). In most cases, only one paralog was documented to be expressed in a broader range of tissues. Moreover, most of the energy metabolism-related gene families (13/18) represented nuclearly encoded mitochondrial proteins (Table 3), many of which had been previously reported in testes-, or, to a much lesser extent, ovary-specific expression datasets (Haerty et al. (2007): 18; Mikhaylova et al (2008): 6; Wasbrough et al. (2010): 14; Gallach et al (2010): 29). revealed that germline-specificity was associated with pronounced protein sequence divergence compared to broadly expressed paralogs in the majority of cases (Supplementary data file 8). As a paradigmatic example, the Heat shock protein 60 (Hsp60) family is represented by the uniformly expressed paralog $H s p 60$ and three testis-biased paralogs in D. melanogaster, i.e. $H s p 60 B, H s p 60 C$, and $H s p 60 D$ (Fig. 4). Maximum likelihood gene tree estimation revealed that the uniformly expressed $D$. melanogaster $H s p 60$ paralog is characterized by a terminal branch length that falls well within the range of that of singleton homologs of other both brachyceran and non-brachyceran species. The testis-biased paralogs, by contrast, which were unique to drosophilid species, were characterized by moderately (Hsp60C) to extremely extended terminal 
500 branch lengths (Hsp60B and Hsp60D) (Fig. 4).

501 Germline subfunctionalization combined with extremely asymmetric protein sequence

502 evolution of sister paralog gene duplicates has been recognized to constitute a signature

503 outcome of intralocus sexual conflict resolution (ISCR) (Haerty et al., 2007; Gallach,

504 Chandrasekaran \& Betrán, 2010). The combined evidence from gene expression and gene tree

505 analyses therefore suggested that the enriched population of duplicated energy metabolism

506 genes had been primarily deployed in ISCR events.

507

508

Molecular signatures of intralocus sexual conflict resolution events throughout schizophoran

509 lineages

510

511

Asking whether the duplication events in energy metabolism gene families had been of

512

general impact in schizophoran Diptera diversity as opposed to specifically the lineage leading

513

to Drosophila, we compared the numbers of independent gene duplications in the 18

514 investigated gene families that were detectable in the terminal branches to schizophoran and

515 non-schizophoran species. As an example, in the Hsp60 gene family two parallel gene

516 duplications mapped to terminal branches of schizophoran species (G. morsitans, T. dalmanni)

517 but no parallel duplications were detectable in the nine sampled non-schizophoran lineages (Fig.

518 4).

519

Overall, we detected 31 independent energy metabolism gene duplications in the

520 terminal branches to the six schizophoran lineages sampled in addition to D. melanogaster. This

521 compared to 9 in the robber fly P. coquilletti and 13 in the 8 non-brachyceran sampled dipteran

522 species (Fig. 3). Outside Diptera, we found 3 parallel duplications in each Apis and Tribolium

523 (Supplementary data file 6). Taken together, these numbers constituted evidence in support of a

524 Schizophora-wide increase in energy metabolism gene duplicate accumulation rate. Moreover,

525 based on the $P$. coquilleti results, also orthorrphaphan Diptera might have experienced a relative

526 increase in energy metabolism gene duplications. Of note, our finding of independent

527 duplications in the Thioredoxin, Hsp60, MME1/colt, and Hexokinase gene families in the stalk

528 eyed fly $T$. dalmanni was consistent with the results of the original study of sperm-enriched

529 genes in T. dalmanni (Baker et al., 2016). Some orthology assignments differed between the 
530 two studies most likely reflecting the uncertainties coming along with low branch support

531 values in some of the respective gene trees (Fig. 4, Supplementary data file 8, and below).

532 Asking whether there was also evidence of ISCR-related trajectories in the population of

533 independent energy metabolism gene duplication events, we tallied the fractions of parallel gene

534 duplications that generated paralogs with pronounced asymmetric, i.e. more than 2-fold, branch

535 length differences based on maximum likelihood tree estimation results. Both parallel

536 brachyceran gene duplications in the Hsp60 gene family, for example, were associated with

537 pronounced asymmetric terminal branch lengths (Fig. 4). Surveying across all energy

538 metabolism related gene families, we found that an average of 3.0 parallel duplications with

539 asymmetrically diverged paralogs in the schizophoran species compared to an average of 1.1

540 among the non-brachyceran dipteran species (Supplementary data 6). Most of the independent

541 gene duplications in the robber fly, however, also produced asymmetrically diverged paralogs

542 (Fig. 3).

543 Comparing the average numbers of gene families in which parallel asymmetric gene

544 duplications were detected indicated a similarly pronounced difference between the

545 schizophoran and non-schizophoran terminal lineages (Fig. 5 and Supplementary data 6). With

546 the caveat of lacking data on the tissue specificities for most of the of the non-Drosophila gene

547 duplicates except for the stalk eyed fly $T$. dalmanni (Baker et al., 2016), these findings did

548 amount to evidence that ISCR via gene duplication has been more common in schizophoran

549 Diptera than in other dipteran lineages with the possible exception of orthorraphan Diptera

550 represented by $P$. coquilleti.

551

552

Pre-schizophoran expansion of the Drosophila Thioredoxin gene family

553

While our analyses indicated a the prevalence of ISCR-related duplications in the energy

554 metabolism gene population during the diversification of schizophoran Diptera, 5 duplications in 3 energy-metabolism gene families predated this time window, based on the compilation of gene family homologs and phylogenetic gene tree analyses (Fig. 3 and Supplementary data file 6). It was therefore of interest to examine whether the protein sequence evolution characteristics of the paralogs resulting from these duplications were likewise indicative of ISCR trajectories despite their considerably more ancient time points of occurrence. 
561

562

563

564

565

566

567

568

569

570

571

572

573

574

575

576

577

578

579

580

581

582

583

584

585

586

587

588

589 oxidoreductase encoding Thioredoxin gene family, which is represented by four paralogs in $D$. melanogaster: Trx-2 (CG31884), Trx-1 (deadhead) (CG4193), TrxT/1 (CG3315), and the yet uncharacterized locus CG13473 (Supplementary data file 6). While $\operatorname{Tr} x$-2 is broadly expressed throughout tissues and life cycle in D. melanogaster, TrxT/1 and CG13473 transcripts are testisenriched while $\operatorname{Tr} x-1$ (dhd) is ovary-enriched (Svensson et al. 2003; Svensson et al. 2007;

Svensson and Larsson 2007).

In most non-schizophoran species, including the robber fly, we only detected singleton Thioredoxin homologs (Fig. 6 and Supplementary data file 6). Multiple homologs were identified in the gall midge species $S$. mosellana and $C$. nasturtii as products of parallel gene duplications based on gene tree analysis results (Fig. 6). Most importantly, in the Mediterranean fruit fly C. capitata, we found candidate 1:1 orthologs for each of the D. melanogaster Thioredoxin gene family members (contig5575_1, contig5575_2, comp62603, comp61885). While branch support values were too low to draw conclusions with high confidence (number of homologous alignment sites: 75; see Supplementary data file 7), the distribution of the $C$. ceratitis Thioredoxin homologs was best compatible with a pre-schizophoran expansion of the D. melanogaster Thioredoxin gene family in light of the fact that the LCA of D. melanogaster and C. ceratitis dates back to the root of schizophoran Diptera (Fig. 3 and 5) (Wiegmann et al., 2011). Further, consistent with the somatic, i.e. likely ancestral, requirement of the $D$. melanogaster Trx-2 paralog, all non-schizophoran homologs clustered with this member of the D. melanogaster Thioredoxin gene family (Fig. 6). The germline-specific TrxT/1, CG13473, and $\operatorname{Tr} x-1$ paralogs, in contrast, each clustered with a large number of bona fide orthologs from schizophoran species (Fig. 6). Thus overall, the gene tree analysis results suggested a preschizophoran ISCR-related expansion of the Thioredoxin gene family.

\section{Ancient ISCR-related expansion of the Malate dehydrogenase 2 gene family}

Results similar to that obtained for the Thioredoxin gene family were encountered for the Malate dehydrogenase 2 (Mdh2) gene family, which comprises two male germline-specific paralogs in D. melanogaster (CG10748, CG10749) besides Mdh2 (CG7998) (Fig. 7). However, unlike in the case of the Thioredoxin, evidence for the existence of not only one but three Mdh2 
590 gene family homologs was found in the robber fly P. coquilletti (Fig. 7 and Supplementary data

591 file 6). One of them, located on genome assembly contig MNCL01000001, grouped basally

592 with the $M d h 2$ homolog cluster while the second, located on genome assembly contig

593 MNCL01000101, branched out basally in the cluster that included the germline-specific $D$.

594 melanogaster homologs CG10748 and CG10749 (Fig. 7 and Supplementary data file 6).

595 Equivalently placed homologs were also recovered from the Mediterranean fruit fly C. capitata 596 (XP 004531266, XP 004536932).

597 The third P. coquilletti Mdh2 gene family homolog located on contig MNCL01000058

598 appeared extremely derived, branching out in the cluster of gall midge (Bibionomorpha) species

599 homologs (Fig. 7). This was likely an artefact due to extreme amino acid substitution

600 differences and limited number of multiple sequence alignments sites (290) for accurate gene

601 tree reconstruction. Notwithstanding these limitations, the existence of reasonably well

602 supported separate orthologs to the somatic and germline-specific paralogs of the $D$.

603 melanogaster Mdh2 gene family in the robber fly P. coquilletti provided compelling evidence of

604 an ISCR-related expansion of this gene family in the stem lineage to brachyceran Diptera, thus

605 over 180 million years ago.

606

607 Early metabolic and late germline-specific expansions of the Hexokinase gene family

608 The oldest duplication event in the energy metabolism gene population was detected in

609 the Hexokinase gene family, which comprises four paralogs in D. melanogaster: Hex-A

610 (CG3001), Hex-C (CG8094), Hex-t1 (CG33102), and Hex-t2 (CG32849) (Fig. 8 and

611 Supplementary data file 6). While Hex-tl and Hex-t2 are germline-specific paralogs, both Hex-

$612 A$ and $H e x-C$ are characterized by high expression levels in a wide number of body regions

613 based on modENCODE data and previous studies (Moser, Johnson \& Lee, 1980; Bourbon et al.,

614 2002; Chen et al., 2014). Moreover, Hex- $A$ is expressed at higher levels than Hex-C in most

615 body regions except for the digestive system, head, and male testis (Chen et al., 2014). This

616 correlates with an ancestral functionality of $H e x-A$ in glucose metabolism in contrast to the

617 derived affinity of Hex-C to fructose (Moser, Johnson \& Lee, 1980).

618 Our homolog searches and gene tree analyses revealed that the broadly expressed Hex-A

619 and Hex-C paralogs were the products of a gene duplication in the LCA of Brachycera and 
620 Bibionomorpha (Fig. 8 and Supplementary data file 6). High confidence orthologs of both Hex-

$621 A$ and $H e x-C$ were detected in all dipteran species sampled with parallel duplications of $H e x-A$

622 in the robber fly (MNCL01000216, MNCL01000057, MNCL01005250_1) and the orange

623 wheat blossom midge S. mosellana (VUAH01006190, VUAH01003649) and parallel

624 duplications of Hex-C in the stalk-eyed fly T. dalmanni (comp147884, comp160205,

625 comp157604) (Fig. 8).

626 Moreover, the Hexokinase gene family tree produced strong support that the germline-

627 specific Hex-t1 and Hex-t2 paralogs were born through additional duplications in the Hex-C

628 cluster (Fig. 8). 1:1 orthologs of each germline-specific paralog, however, were only detectable

629 in D. virilis, thus dating their origin prior to the diversification of drosophilid Diptera. A second

630 cluster of independently duplicated paralogs was detected in the calyptrate species $M$. domestica

631 and G. morsitans (Fig. 8). Only low support, however, was recovered for a closer relationship

632 between these calyptrate Hex-C homologs and the Drosophila Hex-t1/t2 homolog cluster.

633 In summary, the reconstructed sequence of gene duplication events in the Hexokinase

634 gene family corroborated the strong association of ISCR-related gene duplication events with

635 the schizophoran species radiation in addition to revealing an ancient duplication in the LCA of

636 Brachycera and Bibionomorpha that most likely resulted in an expansion of metabolite usage

637 for energy production in these clades.

638

639 Discussion

640

641

Elevated background accumulation of insect core gene duplicates in the higher Diptera

642

643

Studying the impact of gene duplication on phenotypic evolution is of particular interest

644 for understanding the origins of highly diverse organismal groups such as the true flies which

645 encompass over 150,000 described species (Yeates et al., 2007; Wiegmann et al., 2011). Three

646 major radiations have been recognized in the expansion of this megadiverse animal clade.

647 Besides an initial rapid diversification into seven separate lineages approximately 180 million

648 years ago, followed by the radiation of brachyceran Diptera into about 100,000 contemporary

649 species (Wiegmann et al., 2011), roughly 50\% of this diversity was the result of a third 
650 radiation, that of schizophoran Brachycera into over 150 families starting only about 65 million 651 years ago (Wiegmann et al., 2011).

652 Our study was motivated by preliminary evidence that the genome of a premier 653 representative of the Brachycera and Schizophora, i.e. fruit fly D. melanogaster, was notably 654 richer in lineage-specific gene duplicates compared to other equally old or older insect lineages 655 leading to mosquito, beetle, and hymenopteran genome model species (Bao \& Friedrich, 2009; 656 Bao et al., 2018). Our findings at the genome-wide scale presented here point at an 657 approximately 2-fold higher number of duplicated insect core gene in the lineage to Drosophila compared to non-brachyceran Diptera, i.e. mosquitoes (Culicomorpha), honeybee

659 (Hymenoptera), and the red flour beetle (Coleoptera). In addition to our own earlier studies, this result is consistent with multiple notions of Drosophila-specific gene duplications in earlier gene family studies (Svensson, Stenberg \& Larsson, 2007; Porcelli et al., 2007; Bao \&

662 Friedrich, 2009; Carmon \& MacIntyre, 2010; Jiménez-Guri et al., 2013; Fraga et al., 2013;

663 Lewis, Salmela \& Obbard, 2016; Bao et al., 2018; Helleu \& Levine, 2018). At the same time, 664 however, recent large scale analyses of gene duplication rates in insects did not detect evidence 665 of exceptional gene gain in the Drosophila lineage (Li et al., 2018; Thomas et al., 2020). To the 666 contrary, Neafsey et al. (2005) reported a higher gene gain rate in mosquito species compared to 667 drosophilid Diptera. Comparing a similarly small sample of holometabolan insect lineages,

668 Roelofs et al. (2020), however, encountered evidence of a higher genome-wide gene duplication 669 rate in the lineage to Drosophila in comparison to Lepidoptera, Coleoptera, and Hymenoptera. While many high quality insect genome drafts have been generated by now, it is still reasonable to assume that the Drosophila genome continues to be the most comprehensively annotated and best curated one. Therefore, an alternative explanation for the larger number of detected lineage-specific gene duplicates in Drosophila could be lower quality of sequence coverage and gene annotation sensitivity in the genome assemblies of the non-Drosophila species we sampled. Three lines of evidence speak against this possible ascertainment bias: (1) The above mentioned congruence with previous gene-specific studies, (2) the high level of accuracy in our validation test, and (3) the equally high validation in our deeper analyses of gene duplications in energy metabolism gene families. Combined with our analysis of developmental gene families, the same analysis further suggests that the Drosophila-lineage 680 increase of gene duplicate accumulation occurred for the most part during the early stage of the 
681 schizophoran radiation, extending from approximately 65 to 30 million years ago.

682

683 Causation scenarios

684 One obvious followup question arising from our findings is which processes might have

685 been responsible for the enhanced accumulation of duplicated insect core genes in the higher

686 Diptera. The exclusion of adaptive gene family expansions through our focus on small size gene

687 families and the genome-wide dimension of gene duplicate increase makes non-adaptive

688 mechanisms appear more likely. Also the fact that the Drosophila-lineage gene duplicate

689 populations is characterized by the lowest number of enriched BP GO-terms(centered around a

690 single context: energy metabolism), but the highest number of underrepresented BP GO-terms

691 compared to the less core gene duplicate rich lineages could be interpreted in this direction. This

692 finding seems best explained by a gene-function independent origination mechanism that is

693 tolerated to a similar degree by most functional contexts thus explaining the scarcity of enriched

694 biological functions. The relatively high number of underrepresented biological functions could

695 be envisioned to represent functional contexts that are more sensitive to the immediate

696 consequences of gene duplications such as dosage increase. As a point in case, the

697 underrepresentation of developmental functions in the Drosophila population of lineage-specific

698 gene duplicates is consistent with the in most cases highly pleiotropic nature and dosage-

699 sensitive action of developmental regulators, as has been noted in other cases as well (Conant

700 2020). And yet, in the comparison between species Drosophila still stands out with a higher

701 number of developmental gene duplicates (Bao et al., 2018), thus documenting a measurable

702 impact of heightened gene duplicate accumulation even on this exceptionally sensitive

703 functional class of genes.

704 Discounting adaptive forces, the higher proportion of duplicated insect core genes in the

705 Drosophila lineage could be due to an increase in the rate of nonhomologous recombination, an

706 increase in the fixation rate of nascent gene duplicates, or a decrease in gene duplicate loss rates.

707 In principle, all of these candidate variables can be tested through comparative population

708 genomic approaches. Sample sizes will, however, likely need to be considerable in light of the

709 fact that our findings suggest that the 2-fold higher number of insect core gene duplicates in

710 modern Brachycera built over a long evolutionary time span, i.e. up to 65 million years, since

711 the origin of the schizophoran stem lineage and having left traces in less than $10 \%$ of the insect 
712 core gene repertoire.

713 In this context, it is informative to relate our findings to the more recent and dramatic

714 expansion of the pea aphid genee content via local duplications (International Aphid Genomics

715 Consortium, 2010; Armisen et al., 2018; Panfilio et al., 2019). While examples of adaptive gene

716 family expansions have been detected for the pea aphid (Smadja et al., 2009), it is intriguing to

717 note that pea aphids are characterized by cyclical parthenogenesis, i.e. a mode of asexual

718 evolution (Miura et al., 2003). The latter in turn implies relaxed purifying selection due to

719 reduced effective population size, which can be hypothesized to increase the survival

720 probability of nascent gene duplicates via genetic drift (Lynch \& Conery, 2000). While this

721 reference point lends further support to effective population size based mechanisms as candidate

722 explanations of the elevated gene duplicate accumulation in the higher Diptera, population

723 genomic evidence suggests that positive selection has been the stronger effector in the fixation

724 of gene duplicates during the more recent evolutionary history of the genus Drosophila

725 (Cardoso-Moreira et al., 2016). Moreover, while a considerable number of parthenogenesis-

726 capable species have been documented in flies including drosophilids (Meyer et al., 201;

727 Gokhman \& Kuznetsova, 2018), their overall rarity gives little reason to suspect a broader

728 impact of parthenogenesis during the early schizophoran radiation.

729 For these reasons, the recently identified immediate fitness benefit of gene regulatory

730 noise suppression through gene duplications deserves equal consideration as a possible

731 mechanism underlying the schizophoran gene duplicate accumulation increase (Rodrigo \&

732 Fares, 2018). Intriguingly, our study of developmental gene duplications, for instance, produced

733 evidence for a larger amount of long-term conserved, genetically redundant paralogs in the

734 higher Diptera compared to other insect genome models (Bao et al. 2018). This led us to the

735 prediction of a higher level of genetic robustness during development, which might have

736 benefited the comparatively fast speed of embryonic and postembryonic development in the

737 higher Diptera. As noted above, although richer in gene duplicates compared to other insect

738 lineages, developmental genes do not represent a significantly enriched fraction in the

739 population of lineage-specific gene duplicates in Drosophila. It seems therefore reasonable to

740 speculate that much of the functional spectrum of gene duplications in the Drosophila lineage

741 produced a similar blend of conservative vs innovative functionalization outcomes as found for

742 the developmental gene cohort. This prediction can be assessed in future studies through 
743 comprehensive analysis of expression and gene function data available for D. melanogaster.

744 Even more decisive would be the integration of tissue specific expression data from a number of

745 dipteran key species, an approach which proved highly informative in recent studies of gene

746 duplication outcomes in vertebrates (Marlétaz et al., 2018).

Possible links between enhanced gene duplicate accumulation, intralocus sexual conflict resolution, and speciation rates in the higher Diptera

750

Energy metabolism-related genes emerged as the only overrepresented functional category in the brachyceran gene duplicates. As previous studies noted evidence of adaptive evolution of mitochondrially encoded energy metabolism genes associated with the transition to flight in insects (Yang et al., 2014), we initially suspected the emergence of exceptionally fast flight capacities in the brachyceran Diptera as a possible adaptive outcome of the enriched proportion of duplicated energy metabolism genes. Our detailed analysis, however, paints a different picture. With a few notable exceptions in the Thioredoxin and Mdh2 gene families, the energy metabolism gene duplications date to the early diversification of schizophoran Diptera, i.e. over 100 million of years later than the primary radiation of brachyceran Diptera. Moreover, tissue-specificity expression data and asymmetric paralog divergencies identified the great majority of lineage-specific energy metabolism gene duplicates as facilitators of ISCR. Consistent with this, most of our energy metabolism duplicates were previously identified as the genomic products of ISCR (Rand, Clark \& Kann, 2001; Gallach, Chandrasekaran \& Betrán, 2010; Connallon \& Clark, 2011; Wyman, Cutter \& Rowe, 2012; Chakraborty \& Fry, 2015). In this process, the faster sequence divergence of male germline-specific paralogs is thought to be driven to satisfy higher energy requirements of competing sperm, release from conflicting functional constraints, and the higher mutagenic physiology of sperm cells due to higher radical oxygen species production (Rettie \& Dorus, 2012; Patel et al., 2016; Jiang \& Assis, 2017). Of note, ISCR by gene duplication is not considered subfunctionalization in the strict sense of leading to an adaptively neutral breakup of ancestrally pleiotropic functionality (Gallach \& Betrán, 2011). However, it seems commonly assumed, and is testable, that the precursor homologs of ISCR paralogs have been homogeneously expressed in germline and somatic cells, 
774 subfunctions of the ancestral expression repertoire.

775 Overall, our finding of a large number of germline-biased paralogs in the germline-

776 biased energy metabolism genes is of little surprise in light of the fact that over $10 \%$ of the

777 Drosophila coding genome is characterized by germline biased gene expression (Chintapalli,

778 Wang \& Dow, 2007). More remarkable may be our finding that the outcome of ISCR by gene

779 duplication can persist over long evolutionary time spans. The majority of the ISCR-related

780 gene duplications in the lineage to Drosophila mapped to the early radiation of schizophoran

781 Diptera, about 40-60 million years ago. Moreover, the oldest ISCR-related gene duplications

782 captured in our analysis occurred most likely at least 80 million years ago (Mdh2 and

783 Thioredoxin gene families) (Supplementary data file 6). For comparison, the most thoroughly

784 studied case of gene duplication facilitated ISCR studied in Drosophila thus far dates back

785 about 200,000 years (VanKuren \& Long, 2018).

786 Our genomic detection of ISCR associated gene duplicates in subclades of the

787 Drosophila family, i.e. the Drosophila and Sophophora groups, is consistent with the notion

788 that ISCR has continued to be of relevance during the more recent diversification of drosophilid

789 Diptera (Mikhaylova, Nguyen \& Nurminsky, 2008; Kondo et al., 2017). In addition, we

790 detected a considerable number of parallel gene duplications with ISCR signatures, i.e.

791 extremely asymmetrically diverged sister paralogs, in other schizophoran lineages Taken

792 together, these findings and that of others in tephritid Diptera indicate that ISCR has been of

793 widespread occurrence and significance in schizophoran Diptera (Baker et al., 2016).

794 Two lines of evidence indicate a possible link between ISCR frequency and speciation

795 rate in our findings. For one, our data suggest a higher frequency of ISCR in the overall largely

796 expanded schiziphoran Diptera compared to other dipteran clades with exception of the robber

797 fly lineage. Second, we detect evidence of a spike of ISCR related gene duplication events

798 during early schizophoran radiation. Together, tese findings speak to the still open debate of

799 whether ISCR impacts reproductive isolation and therefore ultimately speciation rates (Coyne \&

800 Orr, 1989; Parker \& Partridge, 1998; Gavrilets, 2014). Experimental studies produced mixed

801 signals. Consistent with our results for the higher Diptera, for instance, Katzourakis et al. (

802 2001) found evidence for a correlation between sexual selection and species richness in

803 hoverflies. Similar conclusions have been drawn in a study of tephritid species (Congrains et al.,

804 2018), which aligns taxonomically more closely with our findings of parallel sex biased gene 
805 duplications in schizophoran lineages outside the Drosophilidae. Based on artificial breeding 806 experiments, however, sexual conflict was concluded to play no role in reproductive isolation in 807 D. pseudoobscura (Bacigalupe et al., 2007). At the same time, there is evidence for the action of 808 sexual conflict in allopatric experimental populations of D. melanogaster (Syed et al., 2017). At 809 this point, the available evidence may still be summed up to suggest that speciation rate increase 810 is driven by sexual conflict in some but not all clades (Gavrilets, 2014).

811 In support of the latter notion, we not only detected substantially lower numbers of

812 parallel candidate ISCR gene duplications non-brachyceran Diptera but also in Tribolium and

813 the honeybee, representatives of two megadiverse insect groups. Given the relatively small

814 number and biased selection of gene families sampled, future studies will be needed to

815 scrutinize the preliminary evidence that ISCR may have been of exceptional importance during

816 the radiation of schizophoran Diptera compared to other megadiverse insect groups such as the

817 Hymenoptera and Coleoptera. At this point, however, it is tempting to speculate that a

818 heightened gene duplication background rate fueled ISCR events during the massive radiation

819 of schizophoran Diptera. Encouragingly, our finding that the ISCR promoted germline-

820 specificity of gene duplicates can remain stable over long evolutionary time scales is also of

821 practical significance as it opens up venues for studying the global significance of ISCR in

822 species diversification via comparative genomics and transcriptomics. This promises more

823 definitive answers to the questions raised above and may potentially deliver even generally

824 deeper insights into the role of molecular germ line subfunctionalization in animal speciation

825 (White-Cooper \& Bausek, 2010).

826

827 Conclusions

828 Our comparative analysis of lineage-specific gene duplicates in four holometabolous insect

829 genome species produced evidence of an enhanced gene duplicate accumulation rate in the

830 lineage to Drosophila. Our phylogenetic surveys of developmental and energy metabolism gene

831 duplicates suggest that this increase occurred largely during the diversification of schizophoran

832 Diptera about 60 million years ago. Energy metabolism gene duplicates seem to have

833 experienced an exceptional increase facilitating ISCR via gene duplication, which may also

834 have impacted speciation rates during the early phase of the dramatic schizophoran radiation.

835 Our study further shows that ISCR originated gene duplicates can remain conserved over 
836 considerable evolutionary time scales, which should facilitate broader genomic and

837 transcriptomic studies of the relationship between ISCR and speciation rates.

838

839 Acknowledgements

840 We thank the anonymous reviewers for critical input, Sorin Draghici, Chuanzhou Fan, 841 and Jason Caravas for comments and advice on the project, Wayne State University Scientific 842 Computing Program for providing and maintaining the Grid supercomputing cluster service.

843

844

845

846

847

848

849 
850 References:

851 Altschul SF, Gish W, Miller W, Myers EW, Lipman DJ. 1990. Basic local alignment search tool. Journal 852 of Molecular Biology 215:403-410.

853 Arakane Y, Muthukrishnan S, Kramer KJ, Specht CA, Tomoyasu Y, Lorenzen MD, Kanost M, Beeman

854 RW. 2005. The Tribolium chitin synthase genes TcCHS1 and TcCHS2 are specialized for synthesis

855 of epidermal cuticle and midgut peritrophic matrix. Insect Molecular Biology 14:453-463.

856 Armisen D, Rajakumar R, Friedrich M, Benoit JB. 2018. The genome of the water strider Gerris buenoi

857 reveals expansions of gene repertoires associated with adaptations to life on the water. BMC

$858 \quad$ Genomics 19:832.

859 Ashburner M, Ball CA, Blake JA, Botstein D, Butler H, Cherry JM, Davis AP, Dolinski K, Dwight SS,

860 Eppig JT, Harris MA, Hill DP, Issel-Tarver L, Kasarskis A, Lewis S, Matese JC, Richardson JE,

861 Ringwald M, Rubin GM, Sherlock G. 2000. Gene ontology: tool for the unification of biology. The

862 Gene Ontology Consortium. Nature Genetics 25:25-29.

863 Bacigalupe LD, Crudgington HS, Hunter F, Moore AJ, Snook RR. 2007. Sexual conflict does not drive

864 reproductive isolation in experimental populations of Drosophila pseudoobscura. Journal of

865 Evolutionary Biology 20:1763-1771.

866 Baker RH, Narechania A, DeSalle R, Johns PM, Reinhardt JA, Wilkinson GS. 2016. Spermatogenesis

867 drives rapid gene creation and masculinization of the X chromosome in stalk-eyed flies (Diopsidae).

868 Genome Biology and Evolution 8:896-914.

869 Baker RH, Narechania A, Johns PM, Wilkinson GS. 2012. Gene duplication, tissue-specific gene

870 expression and sexual conflict in stalk-eyed flies (Diopsidae). Philosophical Transactions of the

871 Royal Society of London. Series B, Biological Sciences 367:2357-2375.

872 Bao R, Dia SE, Issa HA, Alhusein D, Friedrich M. 2018. Comparative evidence of an exceptional impact

873 of gene duplication on the developmental evolution of Drosophila and the higher Diptera. Frontiers

874 in Ecology and Evolution 6:63.

875 Bao R, Friedrich M. 2009. Molecular evolution of the Drosophila retinome: exceptional gene gain in the 
higher Diptera. Molecular Biology and Evolution 26:1273-1287.

877 Benjamini Y, Hochberg Y. 1995. Controlling the False Discovery Rate: A practical and powerful

878 approach to multiple testing. Journal of the Royal Statistical Society. Series B, Statistical

$879 \quad$ Methodology 57:289-300.

880 Bourbon H-M, Gonzy-Treboul G, Peronnet F, Alin M-F, Ardourel C, Benassayag C, Cribbs D, Deutsch J,

881 Ferrer P, Haenlin M, Lepesant J-A, Noselli S, Vincent A. 2002. A P-insertion screen identifying

882 novel X-linked essential genes in Drosophila. Mechanisms of Development 110:71-83.

883 Cañestro C, Yokoi H, Postlethwait JH. 2007. Evolutionary developmental biology and genomics. Nature

$884 \quad$ Reviews. Genetics 8:932-942.

885 Cañestro C, Albalat R, Irimia M, Garcia-Fernàndez J. 2013. Impact of gene gains, losses and duplication

886 modes on the origin and diversification of vertebrates. Seminars in Cell \& Developmental Biology

$887 \quad 24: 83-94$.

888 Cardoso-Moreira M, Arguello JR, Gottipati S, Harshman LG, Grenier JK, Clark AG. 2016. Evidence for

889 the fixation of gene duplications by positive selection in Drosophila. Genome Research 26:787-798.

890 Carmon A, MacIntyre R. 2010. The $\alpha$ glycerophosphate cycle in Drosophila melanogaster VI. structure

891 and evolution of enzyme paralogs in the genus Drosophila. The Journal of Heredity 101:225-234.

892 Carroll SB. 1995. Homeotic genes and the evolution of arthropods and chordates. Nature 376:479-485.

893 Castresana J. 2000. Selection of conserved blocks from multiple alignments for their use in phylogenetic $894 \quad$ analysis. Molecular Biology and Evolution 17:540-552.

895 Chakraborty M, Fry JD. 2015. Parallel functional changes in independent testis-specific duplicates of 896 Aldehyde dehydrogenase in Drosophila. Molecular Biology and Evolution 32:1029-1038.

897 Chen Z-X, Sturgill D, Qu J, Jiang H, Park S, Boley N, Suzuki AM, Fletcher AR, Plachetzki DC,

898 FitzGerald PC, Artieri CG, Atallah J, Barmina O, Brown JB, Blankenburg KP, Clough E, Dasgupta

899 A, Gubbala S, Han Y, Jayaseelan JC, Kalra D, Kim Y-A, Kovar CL, Lee SL, Li M, Malley JD,

900 Malone JH, Mathew T, Mattiuzzo NR, Munidasa M, Muzny DM, Ongeri F, Perales L, Przytycka

901 TM, Pu L-L, Robinson G, Thornton RL, Saada N, Scherer SE, Smith HE, Vinson C, Warner CB, 
902 Worley KC, Wu Y-Q, Zou X, Cherbas P, Kellis M, Eisen MB, Piano F, Kionte K, Fitch DH,

903 Sternberg PW, Cutter AD, Duff MO, Hoskins RA, Graveley BR, Gibbs RA, Bickel PJ, Kopp A,

904 Carninci P, Celniker SE, Oliver B, Richards S. 2014. Comparative validation of the D. melanogaster

905 modENCODE transcriptome annotation. Genome Research 24:1209-1223.

906 Chintapalli VR, Wang J, Dow JAT. 2007. Using FlyAtlas to identify better Drosophila melanogaster

907 models of human disease. Nature Genetics 39:715-720.

908 Congrains C, Campanini EB, Torres FR, Rezende VB, Nakamura AM, de Oliveira JL, Lima ALA,

909 Chahad-Ehlers S, Sobrinho IS Jr, de Brito RA. 2018. Evidence of adaptive evolution and relaxed

910 constraints in sex-biased genes of South American and West Indies fruit flies (Diptera: Tephritidae).

911 Genome Biology and Evolution 10:380-395.

912 Connallon T, Clark AG. 2011. The resolution of sexual antagonism by gene duplication. Genetics

913 187:919-937.

914 Coyne JA, Orr HA. 1989. Patterns of speciation in Drosophila. Evolution 43:362-381.

915 Davidson EH, Erwin DH 2006. Gene regulatory networks and the evolution of animal body plans.

916 Science 311:796-800.

917 Dean EJ, Davis JC, Davis RW, Petrov DA. 2008. Pervasive and persistent redundancy among duplicated $918 \quad$ genes in yeast. PLoS Genetics 4:e1000113.

919 Dennis G Jr, Sherman BT, Hosack DA, Yang J, Gao W, Lane HC, Lempicki RA. 2003. DAVID:

920 Database for annotation, visualization, and integrated discovery. Genome Biology 4:P3.

921 Dixit R, Arakane Y, Specht CA, Richard C, Kramer KJ, Beeman RW, Muthukrishnan S. 2008. Domain

922 organization and phylogenetic analysis of proteins from the chitin deacetylase gene family of

923 Tribolium castaneum and three other species of insects. Insect Biochemistry and Molecular Biology

$924 \quad 38: 440-451$.

925 Drăghici S. 2011. Statistics and data analysis for microarrays using $R$ and bioconductor. CRC Press.

926 Drysdale RA, Crosby MA, Consortium F, Others. 2005. FlyBase: genes and gene models. Nucleic Acids

$927 \quad$ Research 33:D390-D395.

Peer) reviewing PDF | (2020:01:44793:2:1:NEW 28 Aug 2020) 
928 Felsenstein J. 2005. PHYLIP version 3.6. Software package, Department of Genome Sciences, University

929 of Washington, Seattle, USA.

930 Finke MD. 2007. Estimate of chitin in raw whole insects. Zoo Biology 26:105-115.

931 Force A, Lynch M, Pickett FB, Amores A, Yan YL, Postlethwait J. 1999. Preservation of duplicate genes 932 by complementary, degenerative mutations. Genetics 151:1531-1545.

933 Foster WA. 1995. Mosquito sugar feeding and reproductive energetics. Annual Review of Entomology

$934 \quad 40: 443-474$.

935 Fraga A, Ribeiro L, Lobato M, Santos V, Silva JR, Gomes H, da Cunha Moraes JL, de Souza Menezes J, 936 de Oliveira CJL, Campos E, da Fonseca RN. 2013. Glycogen and glucose metabolism are essential 937 for early embryonic development of the red flour beetle Tribolium castaneum. PloS One 8:e65125.

938 Gallach M, Chandrasekaran C, Betrán E. 2010. Analyses of nuclearly encoded mitochondrial genes 939 suggest gene duplication as a mechanism for resolving intralocus sexually antagonistic conflict in $940 \quad$ Drosophila. Genome Biology and Evolution 2:835-850.

941 Gallach M, Betrán E. 2011. Intralocus sexual conflict resolved through gene duplication. Trends in $942 \quad$ Ecology \& Evolution 26:222-228.

943 Gavrilets S. 2014. Is sexual conflict an "engine of speciation”? Cold Spring Harbor Perspectives in 944 Biology 6:a017723:1-13.

945 Gokhman VE, Kuznetsova VG. 2018. Parthenogenesis in Hexapoda: holometabolous insects. Journal of $946 \quad$ Zoological Systematics and Evolutionary Research 56:23-34.

947 Griffiths GCD. 1994. Relationships among the major subgroups of Brachycera (Diptera): a critical 948 review. The Canadian Entomologist 126:861-880.

949 Grimaldi D, Engel MS. 2005. Evolution of the insects. Cambridge University Press.

950 Haerty W, Jagadeeshan S, Kulathinal RJ, Wong A, Ravi Ram K, Sirot LK, Levesque L, Artieri CG,

951 Wolfner MF, Civetta A, Singh RS. 2007. Evolution in the fast lane: rapidly evolving sex-related 952 genes in Drosophila. Genetics 177:1321-1335.

953 Hahn MW, Han MV, Han S-G. 2007. Gene family evolution across 12 Drosophila genomes. PLoS 
954

955

956

957

958

959

960

961

962

963

964

965

966

967

968

969

970

971

972

973

974

975

976

977

978

979

Genetics 3:e197.

He S, Del Viso F, Chen C-Y, Ikmi A, Kroesen AE, Gibson MC. 2018. An axial Hox code controls tissue segmentation and body patterning in Nematostella vectensis. Science 361:1377-1380.

Helleu Q, Levine MT. 2018. Recurrent amplification of the Heterochromatin Protein 1 (HP1) gene family across Diptera. Molecular Biology and Evolution. DOI: 10.1093/molbev/msy128.

Holland PWH, Marlétaz F, Maeso I, Dunwell TL, Paps J. 2017. New genes from old: asymmetric divergence of gene duplicates and the evolution of development. Philosophical transactions of the Royal Society of London. Series B, Biological Sciences 372:20150480.

Honeybee Genome Sequencing Consortium. 2006. Insights into social insects from the genome of the honeybee Apis mellifera. Nature 443:931-949.

van Hoof A. 2005. Conserved functions of yeast genes support the duplication, degeneration and complementation model for gene duplication. Genetics 171:1455-1461.

i5K Consortium. 2013. The i5K Initiative: Advancing arthropod genomics for knowledge, human health, agriculture, and the environment. The Journal of Heredity 104:595-600.

Innan H, Kondrashov F. 2010. The evolution of gene duplications: classifying and distinguishing between models. Nature Reviews. Genetics 11:97-108.

International Aphid Genomics Consortium. 2010. Genome sequence of the pea aphid Acyrthosiphon pisum. PLoS Biology 8:e1000313.

International Glossina Genome Initiative. 2014. Genome sequence of the tsetse fly (Glossina morsitans): vector of African trypanosomiasis. Science 344:380-386.

Jiang X, Assis R. 2017. Natural selection drives rapid functional evolution of young Drosophila duplicate genes. Molecular Biology and Evolution 34:3089-3098.

Jiménez-Guri E, Huerta-Cepas J, Cozzuto L, Wotton KR, Kang H, Himmelbauer H, Roma G, Gabaldón T, Jaeger J. 2013. Comparative transcriptomics of early dipteran development. BMC Genomics $14: 123$.

Jiao Y, Wickett NJ, Ayyampalayam S, Chanderbali AS, Landherr L, Ralph PE, Tomsho LP, Hu Y, Liang 

dePamphilis CW. 2011. Ancestral polyploidy in seed plants and angiosperms. Nature 473:97-100.

982 Katzourakis A, Purvis A, Azmeh S, Rotheray G, Gilbert F. 2001. Macroevolution of hoverflies (Diptera: 983 Syrphidae): the effect of using higher-level taxa in studies of biodiversity, and correlates of species 984 richness. Journal of Evolutionary Biology 14:219-227.

985 Kondo S, Vedanayagam J, Mohammed J, Eizadshenass S, Kan L, Pang N, Aradhya R, Siepel A, 986 Steinhauer J, Lai EC. 2017. New genes often acquire male-specific functions but rarely become 987 essential in Drosophila. Genes \& Development 31:1841-1846.

988 Kondrashov FA. 2012. Gene duplication as a mechanism of genomic adaptation to a changing 989 environment. Proceedings of the Royal Society B 279:5048-5057.

990 Labandeira CC, Sepkoski JJ Jr. 1993. Insect diversity in the fossil record. Science 261:310-315.

991 Lan X, Pritchard JK. 2016. Coregulation of tandem duplicate genes slows evolution of 992 subfunctionalization in mammals. Science 352:1009-1013.

993 Larkin MA, Blackshields G, Brown NP, Chenna R, McGettigan PA, McWilliam H, Valentin F, Wallace

994 IM, Wilm A, Lopez R, Thompson JD, Gibson TJ, Higgins DG. 2007. Clustal W and Clustal X

995 version 2.0. Bioinformatics 23:2947-2948.

996

Letunic I, Bork P. 2016. Interactive tree of life (iTOL) v3: an online tool for the display and annotation of 997 phylogenetic and other trees. Nucleic Acids Research 44:W242-5.

998

Lewis EB. 1992. Clusters of master control genes regulate the development of higher organisms. JAMA: The Journal of the American Medical Association 267:1524-1531.

1000 Lewis SH, Salmela H, Obbard DJ. 2016. Duplication and diversification of dipteran Argonaute genes, and 1001 the evolutionary divergence of Piwi and Aubergine. Genome Biology and Evolution 8:507-518.

1002 Li Z, Tiley G, Galuska S, Reardon C, Kidder T, Rundell R, Barker MS. 2018. Multiple large-scale gene 1003 and genome duplications during the evolution of hexapods. Proceedings of the National Academy of 1004 Sciences of the United States of America 115:4713-4718.

1005 Lynch M, Conery JS. 2000. The evolutionary fate and consequences of duplicate genes. Science 
1007 Maere S, Heymans K, Kuiper M. 2005. BiNGO: a Cytoscape plugin to assess overrepresentation of gene 1008 ontology categories in biological networks. Bioinformatics 21:3448-3449.

1009 Marlétaz F, Firbas PN, Maeso I, Tena JJ, Bogdanovic O, Perry M, Wyatt CDR, de la Calle-Mustienes E,

1010 Bertrand S, Burguera D, Acemel RD, van Heeringen SJ, Naranjo S, Herrera-Ubeda C, Skvortsova K, 1011 Jimenez-Gancedo S, Aldea D, Marquez Y, Buono L, Kozmikova I, Permanyer J, Louis A,

1012 Albuixech-Crespo B, Le Petillon Y, Leon A, Subirana L, Balwierz PJ, Duckett PE, Farahani E, Aury

1013 J-M, Mangenot S, Wincker P, Albalat R, Benito-Gutiérrez È, Cañestro C, Castro F, D’Aniello S,

1014 Ferrier DEK, Huang S, Laudet V, Marais GAB, Pontarotti P, Schubert M, Seitz H, Somorjai I,

1015 Takahashi T, Mirabeau O, Xu A, Yu J-K, Carninci P, Martinez-Morales JR, Crollius HR, Kozmik Z,

1016 Weirauch MT, Garcia-Fernàndez J, Lister R, Lenhard B, Holland PWH, Escriva H, Gómez-

1017 Skarmeta JL, Irimia M. 2018. Amphioxus functional genomics and the origins of vertebrate gene

1018 regulation. Nature 564:64-70.

1019 McGarvey PB, Nightingale A, Luo J, Huang H, Martin MJ, Wu C, the UniProt Consortium. 2019.

1020 UniProt genomic mapping for deciphering functional effects of missense variants. Human Mutation $1021 \quad 40: 694-705$.

1022 Meyer RE, Delaage M, Rosset R, Capri M, Aï-Ahmed O. 2010. A single mutation results in diploid 1023 gamete formation and parthenogenesis in a Drosophila yemanuclein-alpha meiosis I defective 1024 mutant. BMC Genetics 11:104.

1025 Mikhaylova LM, Nguyen K, Nurminsky DI. 2008. Analysis of the Drosophila melanogaster testes 1026 transcriptome reveals coordinate regulation of paralogous genes. Genetics 179:305-315.

1027 Miller MA, Pfeiffer W, Schwartz T. 2010. Creating the CIPRES Science Gateway for inference of large 1028 phylogenetic trees. In: 2010 Gateway Computing Environments Workshop (GCE). IEEE, 1-8.

1029 Miura T, Braendle C, Shingleton A, Sisk G, Kambhampati S, Stern DL. 2003. A comparison of

1030 parthenogenetic and sexual embryogenesis of the pea aphid Acyrthosiphon pisum (Hemiptera:

1031 Aphidoidea). Journal of Experimental Zoology 295B:59-81. DOI: 10.1002/jez.b.3. 
1032 Moser D, Johnson L, Lee CY. 1980. Multiple forms of Drosophila hexokinase. Purification, biochemical 1033 and immunological characterization. The Journal of Biological Chemistry 255:4673-4679.

1034 Myers EW, Sutton GG, Delcher AL, Dew IM, Fasulo DP, Flanigan MJ, Kravitz SA, Mobarry CM, 1035 Reinert KH, Remington KA, Anson EL, Bolanos RA, Chou HH, Jordan CM, Halpern AL, Lonardi 1036 S, Beasley EM, Brandon RC, Chen L, Dunn PJ, Lai Z, Liang Y, Nusskern DR, Zhan M, Zhang Q, 1037 Zheng X, Rubin GM, Adams MD, Venter JC. 2000. A whole-genome assembly of Drosophila. $1038 \quad$ Science 287:2196-2204.

1039 Nakatani Y, McLysaght A. 2019. Macrosynteny analysis shows the absence of ancient whole-genome 1040 duplication in lepidopteran insects. Proceedings of the National Academy of Sciences of the United $1041 \quad$ States of America 116:1816-1818.

1042 Neafsey DE, Waterhouse RM, Abai MR, Aganezov SS, Alekseyev MA, Allen JE, Amon J, Arcà B, 1043 Arensburger P, Artemov G, Assour LA, Basseri H, Berlin A, Birren BW, Blandin SA, Brockman AI, 1044 Burkot TR, Burt A, Chan CS, Chauve C, Chiu JC, Christensen M, Costantini C, Davidson VLM, 1045 Deligianni E, Dottorini T, Dritsou V, Gabriel SB, Guelbeogo WM, Hall AB, Han MV, Hlaing T, 1046 Hughes DST, Jenkins AM, Jiang X, Jungreis I, Kakani EG, Kamali M, Kemppainen P, Kennedy RC, 1047 Kirmitzoglou IK, Koekemoer LL, Laban N, Langridge N, Lawniczak MKN, Lirakis M, Lobo NF, 1048 Lowy E, MacCallum RM, Mao C, Maslen G, Mbogo C, McCarthy J, Michel K, Mitchell SN, Moore 1049 W, Murphy KA, Naumenko AN, Nolan T, Novoa EM, O’Loughlin S, Oringanje C, Oshaghi MA, 1050 Pakpour N, Papathanos PA, Peery AN, Povelones M, Prakash A, Price DP, Rajaraman A, Reimer 1051 LJ, Rinker DC, Rokas A, Russell TL, Sagnon N 'fale, Sharakhova MV, Shea T, Simão FA, Simard 1052 F, Slotman MA, Somboon P, Stegniy V, Struchiner CJ, Thomas GWC, Tojo M, Topalis P, Tubio 1053 JMC, Unger MF, Vontas J, Walton C, Wilding CS, Willis JH, Wu Y-C, Yan G, Zdobnov EM, Zhou

1054 X, Catteruccia F, Christophides GK, Collins FH, Cornman RS, Crisanti A, Donnelly MJ, Emrich SJ,

1055 Fontaine MC, Gelbart W, Hahn MW, Hansen IA, Howell PI, Kafatos FC, Kellis M, Lawson D, 1056 Louis C, Luckhart S, Muskavitch MAT, Ribeiro JM, Riehle MA, Sharakhov IV, Tu Z, Zwiebel LJ, 1057 Besansky NJ. 2015. Mosquito genomics. Highly evolvable malaria vectors: the genomes of 16 
Anopheles mosquitoes. Science 347:1258522.

1059 Nene V, Wortman JR, Lawson D, Haas B, Kodira C, Tu ZJ, Loftus B, Xi Z, Megy K, Grabherr M, Ren

1060 Q, Zdobnov EM, Lobo NF, Campbell KS, Brown SE, Bonaldo MF, Zhu J, Sinkins SP, Hogenkamp

1061 DG, Amedeo P, Arensburger P, Atkinson PW, Bidwell S, Biedler J, Birney E, Bruggner RV, Costas

1062 J, Coy MR, Crabtree J, Crawford M, Debruyn B, Decaprio D, Eiglmeier K, Eisenstadt E, El-Dorry

1063 H, Gelbart WM, Gomes SL, Hammond M, Hannick LI, Hogan JR, Holmes MH, Jaffe D, Johnston

1064 JS, Kennedy RC, Koo H, Kravitz S, Kriventseva EV, Kulp D, Labutti K, Lee E, Li S, Lovin DD,

1065 Mao C, Mauceli E, Menck CFM, Miller JR, Montgomery P, Mori A, Nascimento AL, Naveira HF,

1066 Nusbaum C, O’leary S, Orvis J, Pertea M, Quesneville H, Reidenbach KR, Rogers Y-H, Roth CW,

1067 Schneider JR, Schatz M, Shumway M, Stanke M, Stinson EO, Tubio JMC, Vanzee JP, Verjovski-

1068 Almeida S, Werner D, White O, Wyder S, Zeng Q, Zhao Q, Zhao Y, Hill CA, Raikhel AS, Soares

1069 MB, Knudson DL, Lee NH, Galagan J, Salzberg SL, Paulsen IT, Dimopoulos G, Collins FH, Birren

1070 B, Fraser-Liggett CM, Severson DW. 2007. Genome sequence of Aedes aegypti, a major arbovirus

$1071 \quad$ vector. Science 316:1718-1723.

1072 Obbard, D. J., Maclennan, J., Kim, K.-W., Rambaut, A., O'Grady, P. M., and Jiggins, F. M. 2012.

1073 Estimating divergence dates and substitution rates in the Drosophila phylogeny. Molecular Biology

1074 and Evolution 29, 3459-3473.

1075 Ohno S. 1970. Evolution by gene duplication. New York: Springer Verlag.

1076 Pajic P, Pavlidis P, Dean K, Neznanova L, Romano R-A, Garneau D, Daugherity E, Globig A, Ruhl S,

1077 Gokcumen O. 2019. Independent amylase gene copy number bursts correlate with dietary

1078 preferences in mammals. eLife 8. DOI: 10.7554/eLife.44628.

1079 Panfilio KA, Vargas Jentzsch IM, Benoit JB, Erezyilmaz D, Suzuki Y, Colella S, Robertson HM,

1080 Poelchau MF, Waterhouse RM, Ioannidis P, Weirauch MT, Hughes DST, Murali SC, Werren JH,

1081 Jacobs CGC, Duncan EJ, Armisén D, Vreede BMI, Baa-Puyoulet P, Berger CS, Chang C-C, Chao

1082 H, Chen M-JM, Chen Y-T, Childers CP, Chipman AD, Cridge AG, Crumière AJJ, Dearden PK,

1083 Didion EM, Dinh H, Doddapaneni HV, Dolan A, Dugan S, Extavour CG, Febvay G, Friedrich M, 
1084 Ginzburg N, Han Y, Heger P, Holmes CJ, Horn T, Hsiao Y-M, Jennings EC, Johnston JS, Jones TE,

1085 Jones JW, Khila A, Koelzer S, Kovacova V, Leask M, Lee SL, Lee C-Y, Lovegrove MR, Lu H-L,

1086 Lu Y, Moore PJ, Munoz-Torres MC, Muzny DM, Palli SR, Parisot N, Pick L, Porter ML, Qu J,

1087 Refki PN, Richter R, Rivera-Pomar R, Rosendale AJ, Roth S, Sachs L, Santos ME, Seibert J,

1088 Sghaier E, Shukla JN, Stancliffe RJ, Tidswell O, Traverso L, van der Zee M, Viala S, Worley KC,

1089 Zdobnov EM, Gibbs RA, Richards S. 2019. Molecular evolutionary trends and feeding ecology

1090 diversification in the Hemiptera, anchored by the milkweed bug genome. Genome Biology 20:64.

1091 Papanicolaou A, Schetelig MF, Arensburger P, Atkinson PW, Benoit JB, Bourtzis K, Castañera P,

1092 Cavanaugh JP, Chao H, Childers C, Curril I, Dinh H, Doddapaneni H, Dolan A, Dugan S, Friedrich

1093 M, Gasperi G, Geib S, Georgakilas G, Gibbs RA, Giers SD, Gomulski LM, González-Guzmán M,

1094 Guillem-Amat A, Han Y, Hatzigeorgiou AG, Hernández-Crespo P, Hughes DST, Jones JW,

1095 Karagkouni D, Koskinioti P, Lee SL, Malacrida AR, Manni M, Mathiopoulos K, Meccariello A,

1096 Murali SC, Murphy TD, Muzny DM, Oberhofer G, Ortego F, Paraskevopoulou MD, Poelchau M,

1097 Qu J, Reczko M, Robertson HM, Rosendale AJ, Rosselot AE, Saccone G, Salvemini M, Savini G,

1098 Schreiner P, Scolari F, Siciliano P, Sim SB, Tsiamis G, Ureña E, Vlachos IS, Werren JH, Wimmer

1099 EA, Worley KC, Zacharopoulou A, Richards S, Handler AM. 2016. The whole genome sequence of

1100 the Mediterranean fruit fly, Ceratitis capitata (Wiedemann), reveals insights into the biology and

$1101 \quad$ adaptive evolution of a highly invasive pest species. Genome Biology 17:192.

1102 Parker GA, Partridge L. 1998. Sexual conflict and speciation. Philosophical transactions of the Royal

1103 Society of London. Series B, Biological sciences 353:261-274.

1104 Patel MR, Miriyala GK, Littleton AJ, Yang H, Trinh K, Young JM, Kennedy SR, Yamashita YM,

1105 Pallanck LJ, Malik HS. 2016. A mitochondrial DNA hypomorph of cytochrome oxidase specifically

1106 impairs male fertility in Drosophila melanogaster. eLife 5. DOI: 10.7554/eLife.16923.

1107 Pelletier J, Leal WS. 2009. Genome analysis and expression patterns of odorant-binding proteins from the 1108 Southern House mosquito Culex pipiens quinquefasciatus. PloS One 4:e6237.

1109 Porcelli D, Barsanti P, Pesole G, Caggese C. 2007. The nuclear OXPHOS genes in insecta: a common 
1110 evolutionary origin, a common cis-regulatory motif, a common destiny for gene duplicates. $B M C$

$1111 \quad$ Evolutionary Biology 7:215.

1112 Pruitt KD, Tatusova T, Maglott DR. 2005. NCBI Reference Sequence (RefSeq): a curated non-redundant 1113 sequence database of genomes, transcripts and proteins. Nucleic Acids Research 33:D501-4.

1114 Qian W, Zhang J. 2014. Genomic evidence for adaptation by gene duplication. Genome Research $1115 \quad 24: 1356-1362$.

1116 Rand DM, Clark AG, Kann LM. 2001. Sexually antagonistic cytonuclear fitness interactions in

1117 Drosophila melanogaster. Genetics 159:173-187.

1118 Rettie EC, Dorus S. 2012. Drosophila sperm proteome evolution: Insights from comparative genomic 1119 approaches. Spermatogenesis 2:213-223.

1120 Richards S, Gibbs RA, Weinstock GM, Brown SJ, Denell R, Beeman RW, Gibbs R, Beeman RW, Brown

1121 SJ, Bucher G, Friedrich M, Grimmelikhuijzen CJP, Klingler M, Lorenzen M, Richards S, Roth S,

1122 Schröder R, Tautz D, Zdobnov EM, Muzny D, Gibbs RA, Weinstock GM, Attaway T, Bell S, Buhay

1123 CJ, Chandrabose MN, Chavez D, Clerk-Blankenburg KP, Cree A, Dao M, Davis C, Chacko J, Dinh

1124 H, Dugan-Rocha S, Fowler G, Garner TT, Garnes J, Gnirke A, Hawes A, Hernandez J, Hines S,

1125 Holder M, Hume J, Jhangiani SN, Joshi V, Khan ZM, Jackson L, Kovar C, Kowis A, Lee S, Lewis

1126 LR, Margolis J, Morgan M, Nazareth LV, Nguyen N, Okwuonu G, Parker D, Richards S, Ruiz S-J,

1127 Santibanez J, Savard J, Scherer SE, Schneider B, Sodergren E, Tautz D, Vattahil S, Villasana D,

1128 White CS, Wright R, Park Y, Beeman RW, Lord J, Oppert B, Lorenzen M, Brown S, Wang L,

1129 Savard J, Tautz D, Richards S, Weinstock G, Gibbs RA, Liu Y, Worley K, Weinstock G, Elsik CG,

1130 Reese JT, Elhaik E, Landan G, Graur D, Arensburger P, Atkinson P, Beeman RW, Beidler J, Brown

1131 SJ, Demuth JP, Drury DW, Du Y-Z, Fujiwara H, Lorenzen M, Maselli V, Osanai M, Park Y,

1132 Robertson HM, Tu Z, Wang J-J, Wang S, Richards S, Song H, Zhang L, Sodergren E, Werner D,

1133 Stanke M, Morgenstern B, Solovyev V, Kosarev P, Brown G, Chen H-C, Ermolaeva O, Hlavina W,

1134 Kapustin Y, Kiryutin B, Kitts P, Maglott D, Pruitt K, Sapojnikov V, Souvorov A, Mackey AJ,

1135 Waterhouse RM, Wyder S, Zdobnov EM, Zdobnov EM, Wyder S, Kriventseva EV, Kadowaki T, 
1136 Bork P, Aranda M, Bao R, Beermann A, Berns N, Bolognesi R, Bonneton F, Bopp D, Brown SJ,

1137 Bucher G, Butts T, Chaumot A, Denell RE, Ferrier DEK, Friedrich M, Gordon CM, Jindra M,

1138 Klingler M, Lan Q, Lattorff HMG, Laudet V, von Levetsow C, Liu Z, Lutz R, Lynch JA, da Fonseca

1139 RN, Posnien N, Reuter R, Roth S, Savard J, Schinko JB, Schmitt C, Schoppmeier M, Schröder R,

1140 Shippy TD, Simonnet F, Marques-Souza H, Tautz D, Tomoyasu Y, Trauner J, Van der Zee M,

1141 Vervoort M, Wittkopp N, Wimmer EA, Yang X, Jones AK, Sattelle DB, Ebert PR, Nelson D, Scott

1142 JG, Beeman RW, Muthukrishnan S, Kramer KJ, Arakane Y, Beeman RW, Zhu Q, Hogenkamp D,

1143 Dixit R, Oppert B, Jiang H, Zou Z, Marshall J, Elpidina E, Vinokurov K, Oppert C, Zou Z, Evans J,

1144 Lu Z, Zhao P, Sumathipala N, Altincicek B, Vilcinskas A, Williams M, Hultmark D, Hetru C, Jiang

1145 H, Grimmelikhuijzen CJP, Hauser F, Cazzamali G, Williamson M, Park Y, Li B, Tanaka Y, Predel

1146 R, Neupert S, Schachtner J, Verleyen P, Raible F, Bork P, Friedrich M, Walden KKO, Robertson

1147 HM, Angeli S, Forêt S, Bucher G, Schuetz S, Maleszka R, Wimmer EA, Beeman RW, Lorenzen M,

1148 Tomoyasu Y, Miller SC, Grossmann D, Bucher G. 2008. The genome of the model beetle and pest

1149 Tribolium castaneum. Nature 452:949-955.

1150 Rodrigo G, Fares MA. 2018. Intrinsic adaptive value and early fate of gene duplication revealed by a

1151 bottom-up approach. eLife 7. DOI: 10.7554/eLife.29739.

1152 Ryan JF, Mazza ME, Pang K, Matus DQ, Baxevanis AD, Martindale MQ, Finnerty JR. 2007. Pre-

1153 bilaterian origins of the Hox cluster and the Hox code: evidence from the sea anemone, Nematostella

1154 vectensis. PloS One 2:e153.

1155 Saitou N, Nei M. 1987. The neighbor-joining method: a new method for reconstructing phylogenetic

1156 trees. Molecular Biology and Evolution 4:406-425.

1157 Sakuma S, Golan G, Guo Z, Ogawa T, Tagiri A, Sugimoto K, Bernhardt N, Brassac J, Mascher M,

1158 Hensel G, Ohnishi S, Jinno H, Yamashita Y, Ayalon I, Peleg Z, Schnurbusch T, Komatsuda T. 2019.

1159 Unleashing floret fertility in wheat through the mutation of a homeobox gene. Proceedings of the

$1160 \quad$ National Academy of Sciences of the United States of America 116:5182-5187.

1161 Sandve SR, Rohlfs RV, Hvidsten TR. 2018. Subfunctionalization versus neofunctionalization after 
1162 whole-genome duplication. Nature Genetics 50:908-909.

1163 Schlicker A, Domingues FS, Rahnenführer J, Lengauer T. 2006. A new measure for functional similarity 1164 of gene products based on Gene Ontology. BMC Bioinformatics 7:302.

1165 Schwager EE, Sharma PP, Clarke T, Leite DJ, Wierschin T, Pechmann M, Akiyama-Oda Y, Esposito L,

1166 Bechsgaard J, Bilde T, Buffry AD, Chao H, Dinh H, Doddapaneni H, Dugan S, Eibner C, Extavour

1167 CG, Funch P, Garb J, Gonzalez LB, Gonzalez VL, Griffiths-Jones S, Han Y, Hayashi C, Hilbrant M,

1168 Hughes DST, Janssen R, Lee SL, Maeso I, Murali SC, Muzny DM, Nunes da Fonseca R, Paese

1169 CLB, Qu J, Ronshaugen M, Schomburg C, Schönauer A, Stollewerk A, Torres-Oliva M, Turetzek N,

1170 Vanthournout B, Werren JH, Wolff C, Worley KC, Bucher G, Gibbs RA, Coddington J, Oda H,

1171 Stanke M, Ayoub NA, Prpic N-M, Flot J-F, Posnien N, Richards S, McGregor AP. 2017. The house

1172 spider genome reveals an ancient whole-genome duplication during arachnid evolution. BMC

$1173 \quad$ Biology 15:62.

1174 Scott JG, Warren WC, Beukeboom LW, Bopp D, Clark AG, Giers SD, Hediger M, Jones AK, Kasai S,

1175 Leichter CA, Li M, Meisel RP, Minx P, Murphy TD, Nelson DR, Reid WR, Rinkevich FD,

1176 Robertson HM, Sackton TB, Sattelle DB, Thibaud-Nissen F, Tomlinson C, van de Zande L, Walden

1177 KKO, Wilson RK, Liu N. 2014. Genome of the house fly, Musca domestica L., a global vector of

1178 diseases with adaptations to a septic environment. Genome Biology 15:466.

1179 Sharakhova MV, Hammond MP, Lobo NF, Krzywinski J, Unger MF, Hillenmeyer ME, Bruggner RV,

1180 Birney E, Collins FH. 2007. Update of the Anopheles gambiae PEST genome assembly. Genome

$1181 \quad$ Biology 8:R5.

1182 Sievers F, Wilm A, Dineen D, Gibson TJ, Karplus K, Li W, Lopez R, McWilliam H, Remmert M, Söding

1183 J, Thompson JD, Higgins DG. 2011. Fast, scalable generation of high-quality protein multiple

1184 sequence alignments using Clustal Omega. Molecular Systems Biology 7. DOI:

$1185 \quad 10.1038 / \mathrm{msb} .2011 .75$.

1186 Smadja C, Shi P, Butlin RK, Robertson HM. 2009. Large gene family expansions and adaptive evolution

1187 for odorant and gustatory receptors in the pea aphid, Acyrthosiphon pisum. Molecular Biology and

Peer) reviewing PDF | (2020:01:44793:2:1:NEW 28 Aug 2020) 
1189 Smoot ME, Ono K, Ruscheinski J, Wang P-L, Ideker T. 2011. Cytoscape 2.8: new features for data $1190 \quad$ integration and network visualization. Bioinformatics 27:431-432.

1191 Stamatakis A. 2014. RAxML version 8: a tool for phylogenetic analysis and post-analysis of large 1192 phylogenies. Bioinformatics 30:1312-1313.

1193 Supek F, Bošnjak M, Škunca N, Šmuc T. 2011. REVIGO summarizes and visualizes long lists of gene 1194 ontology terms. PloS One 6:e21800.

1195 Suyama M, Torrents D, Bork P. 2006. PAL2NAL: robust conversion of protein sequence alignments into 1196 the corresponding codon alignments. Nucleic Acids Research 34:W609-12.

1197 Svensson MJ, Stenberg P, Larsson J. 2007. Organization and regulation of sex-specific thioredoxin 1198 encoding genes in the genus Drosophila. Development Genes and Evolution 217:639-650.

1199 Syed ZA, Chatterjee M, Samant MA, Prasad NG. 2017. Reproductive isolation through experimental 1200 manipulation of sexually antagonistic coevolution in Drosophila melanogaster. Scientific Reports $1201 \quad 7: 3330$.

1202 Talavera G, Castresana J. 2007. Improvement of phylogenies after removing divergent and ambiguously 1203 aligned blocks from protein sequence alignments. Systematic Biology 56:564-577.

1204 The Gene Ontology Consortium. 2015. Gene Ontology Consortium: going forward. Nucleic Acids $1205 \quad$ Research 43:D1049-D1056.

1206 Thomas GWC, Dohmen E, Hughes DST, Murali SC, Poelchau M, Glastad K, Anstead CA, Ayoub NA, 1207 Batterham P, Bellair M, Binford GJ, Chao H, Chen YH, Childers C, Dinh H, Doddapaneni HV, 1208 Duan JJ, Dugan S, Esposito LA, Friedrich M, Garb J, Gasser RB, Goodisman MAD, Gundersen1209 Rindal DE, Han Y, Handler AM, Hatakeyama M, Hering L, Hunter WB, Ioannidis P, Jayaseelan JC, 1210 Kalra D, Khila A, Korhonen PK, Lee CE, Lee SL, Li Y, Lindsey ARI, Mayer G, McGregor AP, 1211 McKenna DD, Misof B, Munidasa M, Munoz-Torres M, Muzny DM, Niehuis O, Osuji-Lacy N, Palli 1212 SR, Panfilio KA, Pechmann M, Perry T, Peters RS, Poynton HC, Prpic N-M, Qu J, Rotenberg D, 1213 Schal C, Schoville SD, Scully ED, Skinner E, Sloan DB, Stouthamer R, Strand MR, Szucsich NU, 
1214 Wijeratne A, Young ND, Zattara EE, Benoit JB, Zdobnov EM, Pfrender ME, Hackett KJ, Werren

1215 JH, Worley KC, Gibbs RA, Chipman AD, Waterhouse RM, Bornberg-Bauer E, Hahn MW, Richards

1216 S. 2020. Gene content evolution in the arthropods. Genome Biology 21:15.

1217 VanKuren NW, Long M. 2018. Gene duplicates resolving sexual conflict rapidly evolved essential 1218 gametogenesis functions. Nature Ecology \& Evolution 2:705-712.

1219 Vicoso B, Bachtrog D. 2015. Numerous transitions of sex chromosomes in Diptera. PLoS Biology $1220 \quad 13: \mathrm{e} 1002078$.

1221 Wang J, Tao F, Marowsky NC, Fan C. 2016. Evolutionary fates and dynamic functionalization of young 1222 duplicate genes in Arabidopsis genomes. Plant Physiology 172:427-440.

1223 Wasbrough ER, Dorus S, Hester S, Howard-Murkin J, Lilley K, Wilkin E, Polpitiya A, Petritis K, Karr

1224 TL. 2010. The Drosophila melanogaster sperm proteome-II (DmSP-II). Journal of Proteomics

$1225 \quad 73: 2171-2185$.

1226 Whelan S, Goldman N. 2001. A general empirical model of protein evolution derived from multiple

1227 protein families using a maximum-likelihood approach. Molecular Biology and Evolution 18:691699.

1229 White-Cooper H, Bausek N. 2010. Evolution and spermatogenesis. Philosophical Transactions of the 1230 Royal Society of London. Series B, Biological Sciences 365:1465-1480.

1231 Wiegmann BM, Trautwein MD, Winkler IS, Barr NB, Kim J-W, Lambkin C, Bertone MA, Cassel BK,

1232 Bayless KM, Heimberg AM, Wheeler BM, Peterson KJ, Pape T, Sinclair BJ, Skevington JH,

1233 Blagoderov V, Caravas J, Kutty SN, Schmidt-Ott U, Kampmeier GE, Thompson FC, Grimaldi DA, 1234 Beckenbach AT, Courtney GW, Friedrich M, Meier R, Yeates DK. 2011. Episodic radiations in the 1235 fly tree of life. Proceedings of the National Academy of Sciences of the United States of America $1236 \quad 108: 5690-5695$.

1237 Wyman MJ, Cutter AD, Rowe L. 2012. Gene duplication in the evolution of sexual dimorphism. 1238 Evolution 66:1556-1566.

1239 Yang Z. 2007. PAML 4: phylogenetic analysis by maximum likelihood. Molecular Biology and Evolution 
24:1586-1591.

1241 Yang Y, Xu S, Xu J, Guo Y, Yang G. 2014. Adaptive evolution of mitochondrial energy metabolism

1242 genes associated with increased energy demand in flying insects. PloS One 9:e99120.

1243 Yeates DK, Wiegmann BM, Courtney GW, Meier R, Lambkin C, Pape T. 2007. Phylogeny and

1244 systematics of Diptera: two decades of progress and prospects. Zootaxa 1668:565-590.

1245 Yin C, Shen G, Guo D, Wang S, Ma X, Xiao H, Liu J, Zhang Z, Liu Y, Zhang Y, Yu K, Huang S, Li F.

1246 2016. InsectBase: a resource for insect genomes and transcriptomes. Nucleic Acids Research

$1247 \quad 44: D 801-7$.

1248 Zhang Y-J, Hao Y, Si F, Ren S, Hu G, Shen L, Chen B. 2014. The de novo transcriptome and its analysis

1249 in the worldwide vegetable pest, Delia antiqua (Diptera: Anthomyiidae). G3 4:851-859.

1250 Zhao C, Escalante LN, Chen H, Benatti TR, Qu J, Chellapilla S, Waterhouse RM, Wheeler D, Andersson

1251 MN, Bao R, Batterton M, Behura SK, Blankenburg KP, Caragea D, Carolan JC, Coyle M, El-

1252 Bouhssini M, Francisco L, Friedrich M, Gill N, Grace T, Grimmelikhuijzen CJP, Han Y, Hauser F,

1253 Herndon N, Holder M, Ioannidis P, Jackson L, Javaid M, Jhangiani SN, Johnson AJ, Kalra D,

1254 Korchina V, Kovar CL, Lara F, Lee SL, Liu X, Löfstedt C, Mata R, Mathew T, Muzny DM, Nagar

1255 S, Nazareth LV, Okwuonu G, Ongeri F, Perales L, Peterson BF, Pu L-L, Robertson HM,

1256 Schemerhorn BJ, Scherer SE, Shreve JT, Simmons D, Subramanyam S, Thornton RL, Xue K,

1257 Weissenberger GM, Williams CE, Worley KC, Zhu D, Zhu Y, Harris MO, Shukle RH, Werren JH,

1258 Zdobnov EM, Chen M-S, Brown SJ, Stuart JJ, Richards S. 2015. A massive expansion of effector

1259 genes underlies gall-formation in the wheat pest Mayetiola destructor. Current Biology: CB 25:613-

$1260 \quad 620$.

1261

1262

1263

Peer) reviewing PDF | (2020:01:44793:2:1:NEW 28 Aug 2020) 
1267 Figure 1: Lineage-specific core gene duplicate numbers across holometabolous insect genome model species. Boxes on terminal branches in the species tree report the numbers of gene families with lineage-specific gene duplications: Drosophila melanogaster $=$ Dmel, Anopheles gambiae = Agam, Tribolium castaneum $=$ Tcas, Apis mellifera $=$ Amel. Bar charts depict distributions of lineage-specific gene duplicates by age based on neutral substitution divergence $(\mathrm{dS})$ estimates with $\mathrm{Y}$-axis representing the number of duplicates associated with each dS value bin.

Figure 2. Functional enrichment analysis of lineage-specific gene duplicates. Distribution of GO functional categories in the duplicates of Drosophila melanogaster (Pre-Brachyceran and Brachyceran), Anopheles gambiae, Tribolium castaneum, and Apis mellifera. Bars represent abundance of genes associated with each listed individual GO term in the duplicates relative to those among all investigated genes (both singletons and duplicates) from each species. Relative abundance equal to 1 (background orange range) indicates that the GO term abundance in the duplicated genes is comparable to that in all genes, while a value lower than or higher than 1 indicates under- or over-representation, respectively. Brachyceran over-represented GO terms refer to the group of GO terms enriched in Brachycera-specific duplicates based on analysis of homolog conservation in $M$. destructor.

Figure 3. Phylogenetic accumulation of brachyceran energy metabolism gene duplicates. Summary of gene duplication time points based on homolog conservation in the species included in gene tree analysis. The Brachycera portion of the tree is indicated by dark grey branches. Dark grey numbers at branches indicate duplication events that generated conserved duplicates in the lineage to D. melanogaster. Light grey numbers at branches indicate parallel gene duplication events. Topology and branching time points based on Wiegmann et al. (2011). mya $=$ million years ago. Maximum likelihood tree of Hsp60 gene family homologs compiled from dipteran species and select non-dipteran outgroup species (Amel, Tcas). Numbers at branches represent branch support from non-parametric bootstrap analysis. Branch support values lower than 50\% not shown. The four Hsp60 paralogs of D. melanogaster are highlighted in bold font. Orange branches indicate germline-specific paralogs. Red branches indicate parallel duplications. Species abbreviations: Aaed $=$ Aedes aegypti, Agam $=$ Anopheles gambiae, Ccap $=$ Ceratitis capitata, Cnas $=$ Contarinia nasturtii, Cqui $=$ Culex quinquefasciatus, Dant $=$ Delia antiqua, Dmel $=$ Drosophila melanogaster, Dvir $=$ Drosophila virilis, Gmor $=$ Glossina morsitans $;$ Llon =Lutzomyia longipalpis, Mdes = Mayetiola destructor, Mdom = Musca domestica, Ppap = Phlebotomus papatasi, Pcoq $=$ Proctacanthus coquilletti, Smos = Sitodiplosis mosellana, Tdal $=$ Teleopsis dalmanni. Note: We failed to detect Hsp60D in D. virilis but found Hsp60D in the closely related $D$. willistoni implying that $H s p 60 D$ originated through a duplication that preceded the split of the Sophophora and Drosophila subgroups, which are represented by $D$. melanogaster vs D. virilis and D. willistoni, respectively. Scale bar corresponds to 0.1 
1309

1310

1311

1312

1313

1314

1315

1316

1317

1318

1319

1320

1321

1322

1323

1324

1325

1326

1327

1328

1329

1330

1331

1332

1333

1334

1335

1336

1337

1338

1339

1340

1341

1342

1343

1344

substitutions per site.

Figure 5. Taxonomic survey of parallel duplications in the population of Drosophila lineage-specific expanded energy metabolism gene families. Numbers in parentheses next to species names indicate numbers of gene families sampled followed by the number of parallel gene duplications that produced equally diverged paralogs (represented as a percentage of all gene families sampled by blue bar portions) and the number of parallel duplications with strong branch asymmetry $(>2)$ between sister paralogs (represented as a percentage of all gene families sampled by red bar portions).

Figure 6. Dipteran Thioredoxin gene family tree. Maximum likelihood tree of Thioredoxin homologs compiled from dipteran species and select outgroup species. Numbers at branches represent branch support from non-parametric bootstrap analysis. Branch support values lower than $10 \%$ not shown. The four Thioredoxin gene family paralogs of D. melanogaster are highlighted in bold font. Orange branches indicate germline-specific paralogs in Drosophila. Red branches indicate originated asymmetric gene duplicates that originated in parallel to the duplications in the Drosophila lineage. Purple branches lead to robber fly homologs. Species abbreviations same as in Figure 4. Scale bar corresponds to 0.1 substitutions per site.

Figure 7. Dipteran Mdh2 gene family tree. Maximum likelihood tree of $M d h 2$ homologs compiled from dipteran species and select outgroup species. Numbers at branches represent branch support from non-parametric bootstrap analysis. Branch support values lower than 50\% not shown. Orange branches indicate germline-specific paralogs in the Drosophila lineage. Blue branches lead to robber fly homologs. Species abbreviations as in Figure 4. Scale bar corresponds to 0.1 substitutions per site.

Figure 8. Dipteran Hexokinase gene family tree. Maximum likelihood tree of Hexokinase homologs compiled from dipteran and select outgroup species. Numbers at branches represent branch support from non-parametric bootstrap analysis. Branch support values lower than 50\% not shown. Orange branches indicate germline-specific paralogs in the Drosophila lineage. Blue branches lead to robber fly homologs. Turquoise branches indicate gall midge (Bibionomorpha) homolog clusters. Species abbreviations same as in Figure 4. Scale bar corresponds to 0.1 substitutions per site. 
1345 Table 1: Lineage-specific gene duplications in insect core gene families. Species name 1346 abbreviations as in Figure 1. Species-specific cell entries represent percentages of lineage1347 specific expanded gene families sorted by post-duplication size (2-6) with absolute numbers 1348 given in parentheses. Total percentages of lineage-specific expanded gene families given with 1349 absolute numbers and number of sampled gene families in parentheses. metabolism gene families. Rates calculated as average numbers of duplications per gene family per million years. See Figure 4 for branch definitions. Time intervals based on Wiegmann et al. (2011) and Obbard et al. (2012).

1356 Table 3: Paralog expression specificities in expanded energy metabolism gene families. 
Figure 1

Lineage-specific core gene duplicate numbers across holometabolous insect genome model species

Boxes on terminal branches in the species tree report the numbers of gene families with lineage-specific gene duplications: Drosophila melanogaster $=$ Dmel, Anopheles gambiae $=$ Agam, Tribolium castaneum $=$ Tcas, Apis mellifera $=$ Amel. Bar charts depict distributions of lineage-specific gene duplicates by age based on neutral substitution divergence (dS) estimates with Y-axis representing the number of duplicates associated with each dS value bin. 


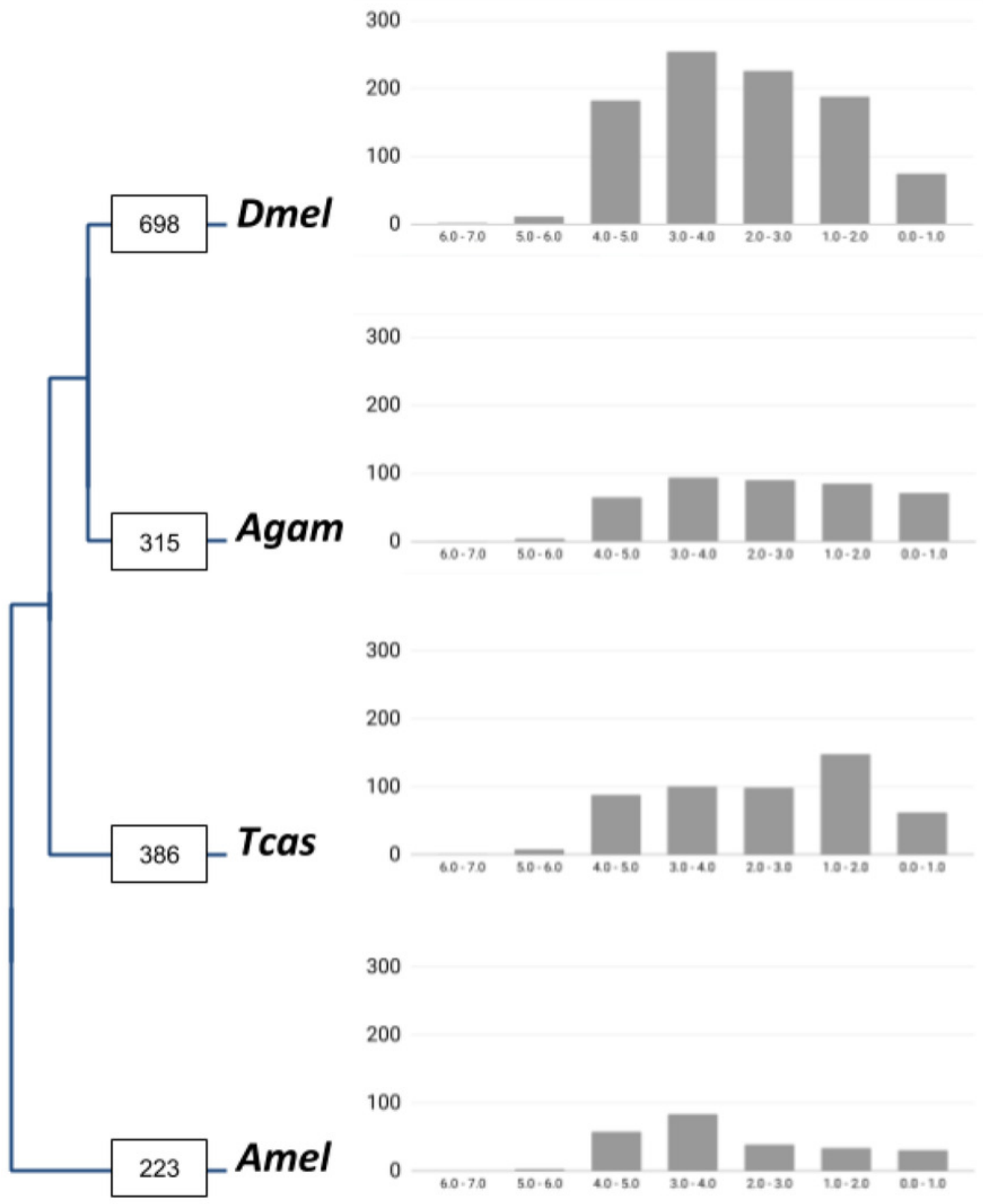




\section{Figure 2}

Functional enrichment analysis of lineage-specific gene duplicates

Distribution of GO functional categories in the duplicates of Drosophila melanogaster (PreBrachyceran and Brachyceran), Anopheles gambiae, Tribolium castaneum, and Apis mellifera. Bars represent abundance of genes associated with each listed individual GO term in the duplicates relative to those among all investigated genes (both singletons and duplicates) from each species. Relative abundance equal to 1 (background orange range) indicates that the GO term abundance in the duplicated genes is comparable to that in all genes, while a value lower than or higher than 1 indicates under- or over-representation, respectively. Brachyceran over-represented GO terms refer to the group of GO terms enriched in Brachycera-specific duplicates based on analysis of homolog conservation in $M$. destructor. 


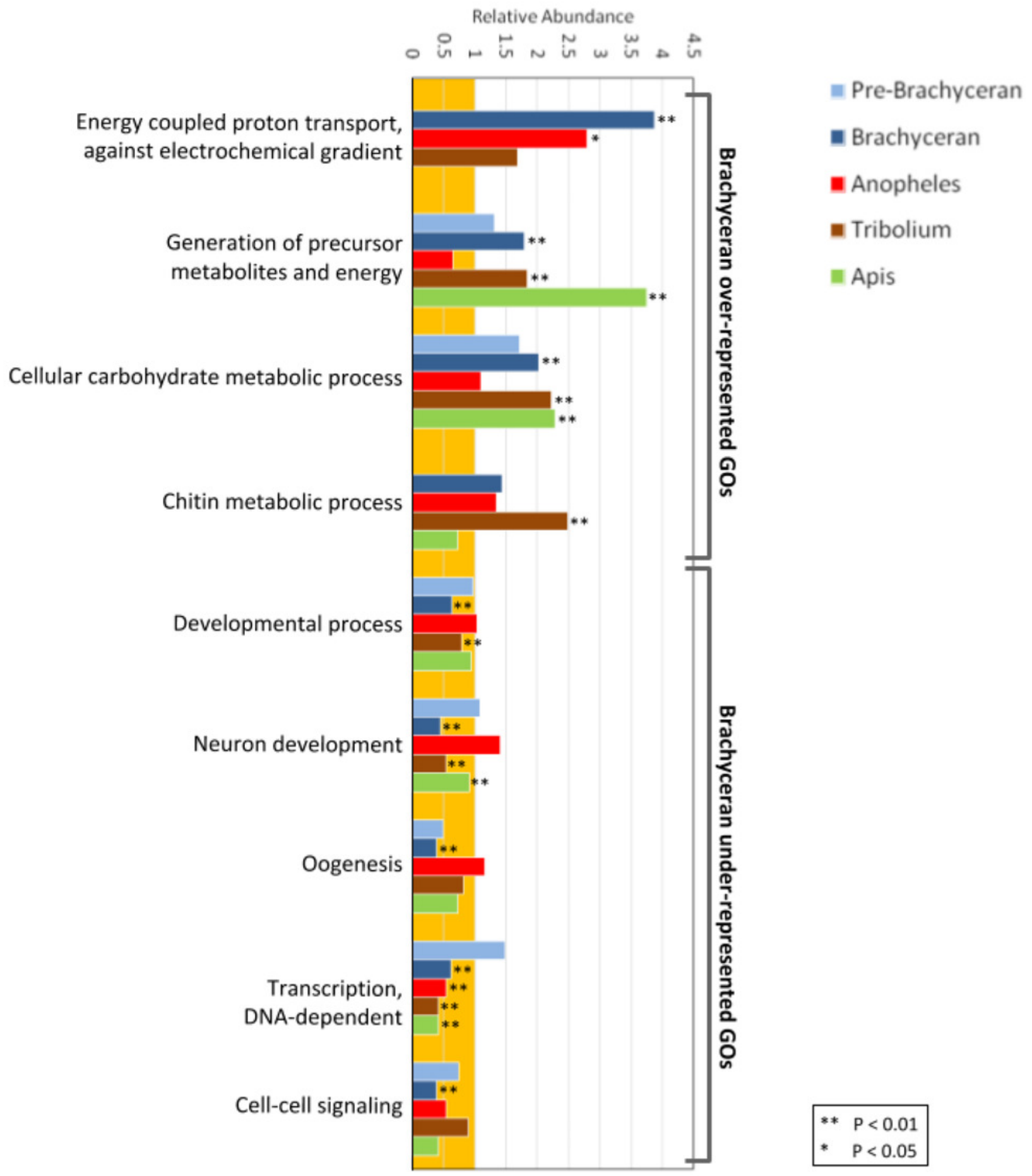




\section{Figure 3}

Phylogenetic accumulation of brachyceran energy metabolism gene duplicates

Summary of gene duplication time points based on homolog conservation in the species included in gene tree analysis. The Brachycera portion of the tree is indicated by dark grey branches. Dark grey numbers at branches indicate duplication events that generated conserved duplicates in the lineage to D. melanogaster. Light grey numbers at branches indicate parallel gene duplication events. Topology and branching time points based on Wiegmann et al. (2011). mya = million years ago.

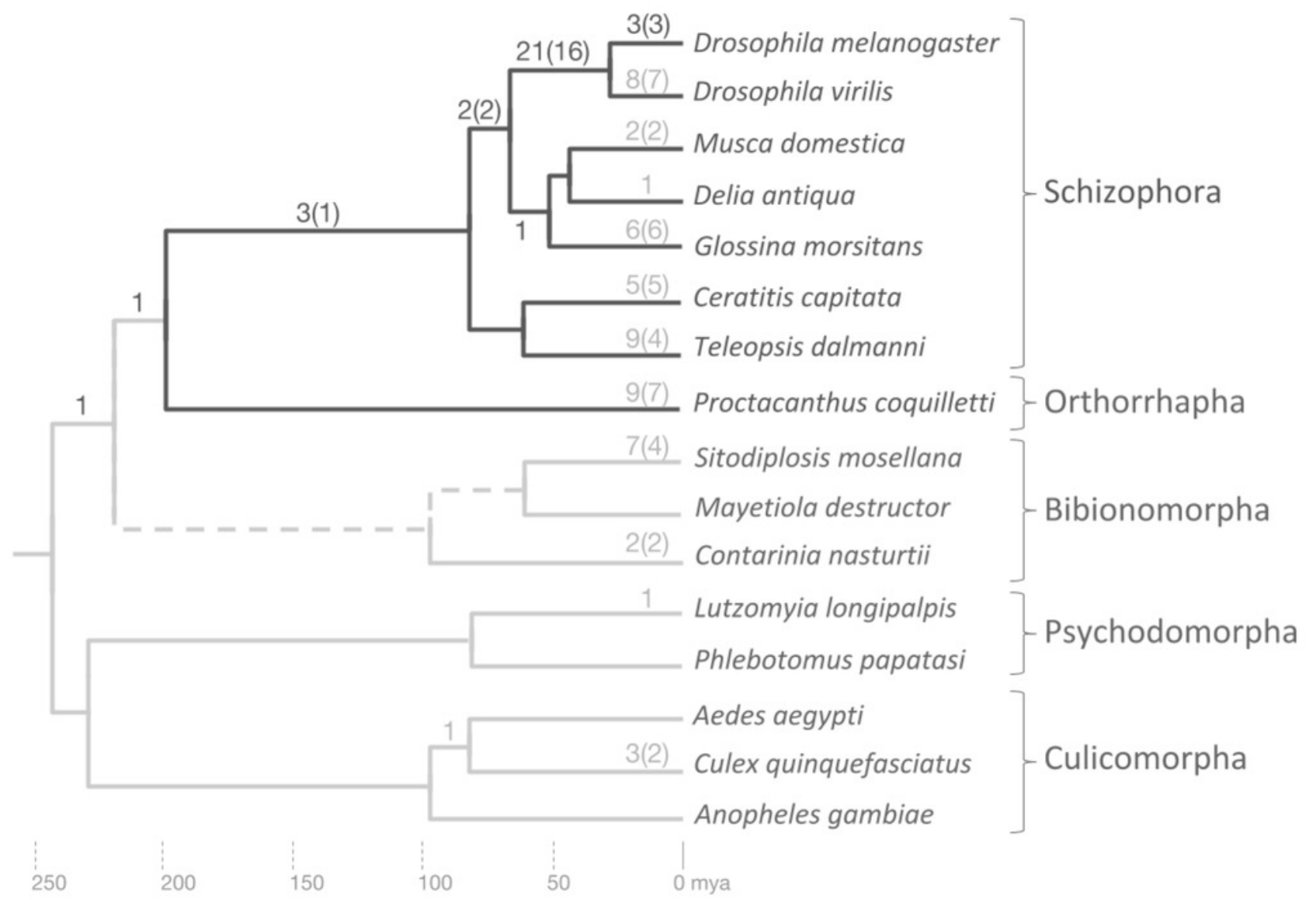




\section{Figure 4}

Expansion and diversification of the Hsp60 gene family in schizophoran Diptera

Maximum likelihood tree of $\mathrm{Hsp60}$ gene family homologs compiled from dipteran species and select non-dipteran outgroup species (Amel, Tcas). Numbers at branches represent branch support from non-parametric bootstrap analysis. Branch support values lower than $50 \%$ not shown. The four Hsp60 paralogs of D. melanogaster are highlighted in bold font. Orange branches indicate germline-specific paralogs. Red branches indicate parallel duplications. Species abbreviations: Aaed $=$ Aedes aegypti, Agam $=$ Anopheles gambiae, Ccap $=$ Ceratitis capitata, Cnas = Contarinia nasturtii, Cqui = Culex quinquefasciatus, Dant = Delia antiqua, Dmel = Drosophila melanogaster, Dvir = Drosophila virilis, Gmor = Glossina morsitans; Llon $=$ Lutzomyia longipalpis, Mdes = Mayetiola destructor, Mdom = Musca domestica, Ppap = Phlebotomus papatasi, Pcoq = Proctacanthus coquilletti, Smos = Sitodiplosis mosellana, Tdal = Teleopsis dalmanni. Note: We failed to detect Hsp60D in D. virilis but found Hsp60D in the closely related $D$. willistoni implying that $H s p 60 D$ originated through a duplication that preceded the split of the Sophophora and Drosophila subgroups, which are represented by $D$. melanogaster vs $D$. virilis and $D$. willistoni, respectively. Scale bar corresponds to 0.1 substitutions per site. 


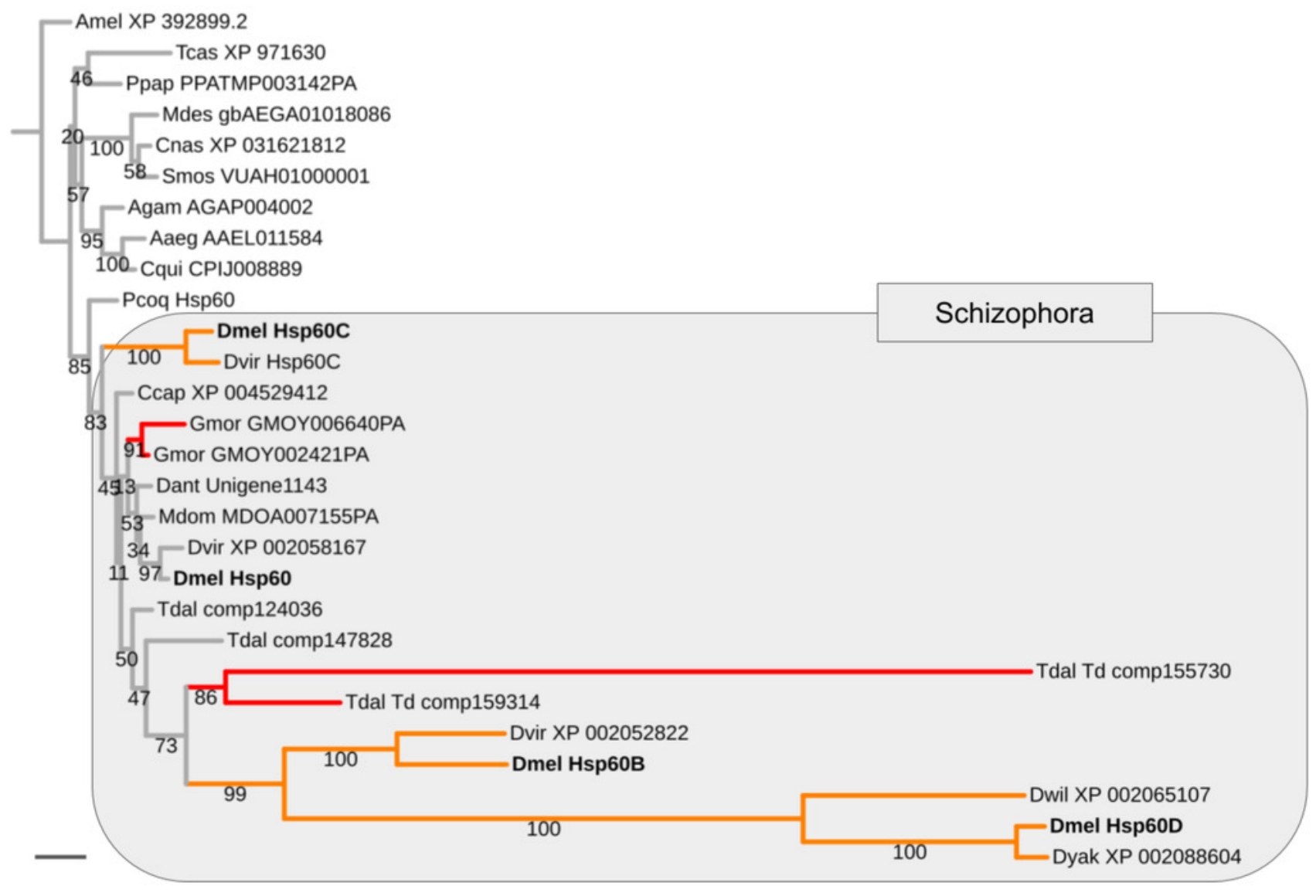




\section{Figure 5}

Taxonomic survey of parallel duplications in the overrepresented energy metabolism gene family populations of Brachycera-specific gene duplicates

Numbers in parentheses next to species names indicate numbers of gene families sampled followed by the number of parallel gene duplications that produced equally diverged paralogs (represented as a percentage of all gene families sampled by blue bar portions) and the number of parallel duplications with strong branch asymmetry $(>2)$ between sister paralogs (represented as a percentage of all gene families sampled by red bar portions).

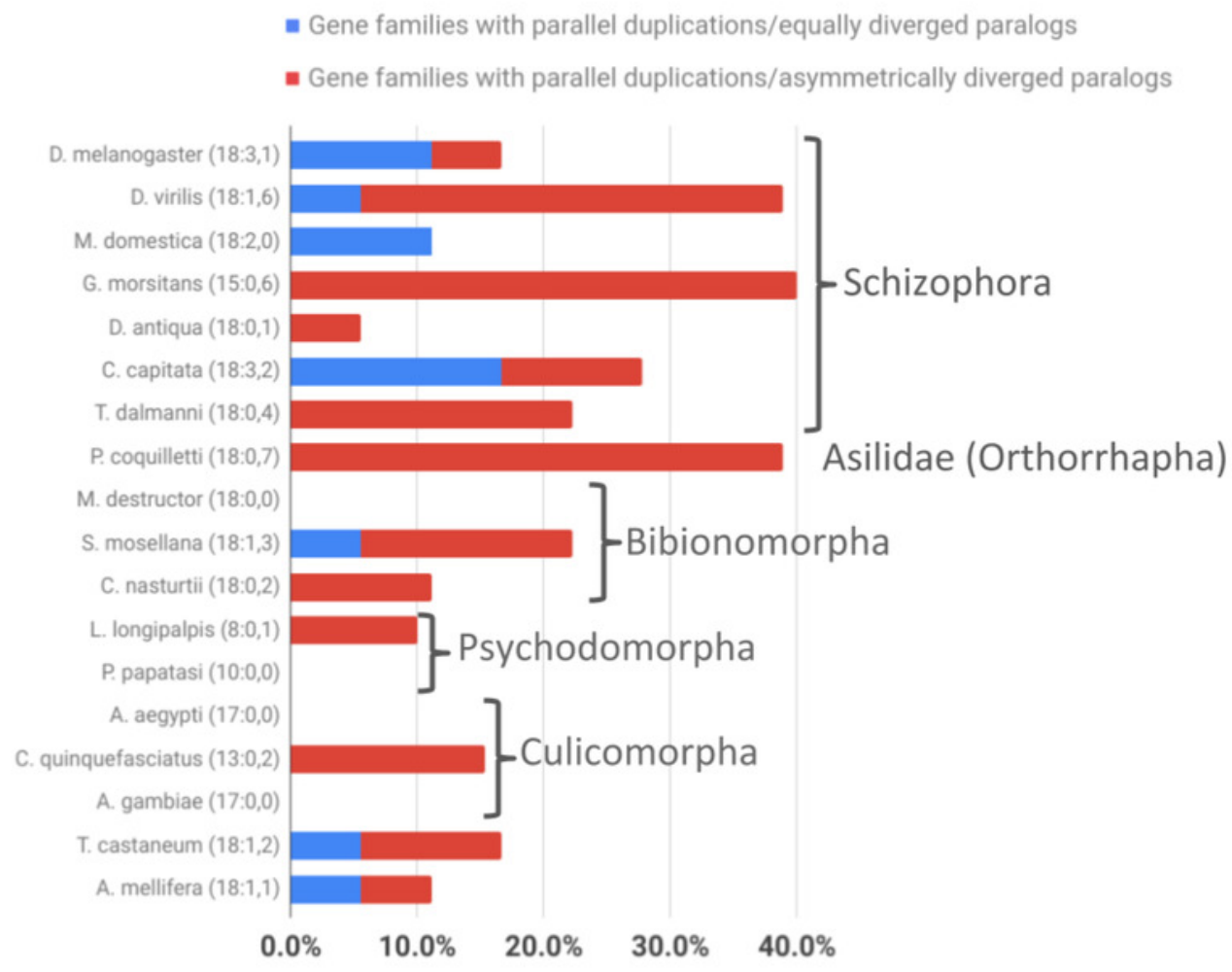




\section{Figure 6}

Dipteran Thioredoxin gene family tree

Maximum likelihood tree of Thioredoxin homologs compiled from dipteran species and select outgroup species. Numbers at branches represent branch support from non-parametric bootstrap analysis. Branch support values lower than $10 \%$ not shown. The four Thioredoxin gene family paralogs of $D$. melanogaster are highlighted in bold font. Orange branches indicate germline-specific paralogs in Drosophila. Red branches indicate originated asymmetric gene duplicates that originated in parallel to the duplications in the Drosophila lineage. Purple branches lead to robber fly homologs. Species abbreviations same as in Figure 4 . Scale bar corresponds to 0.1 substitutions per site. 
Amel XP 003250408

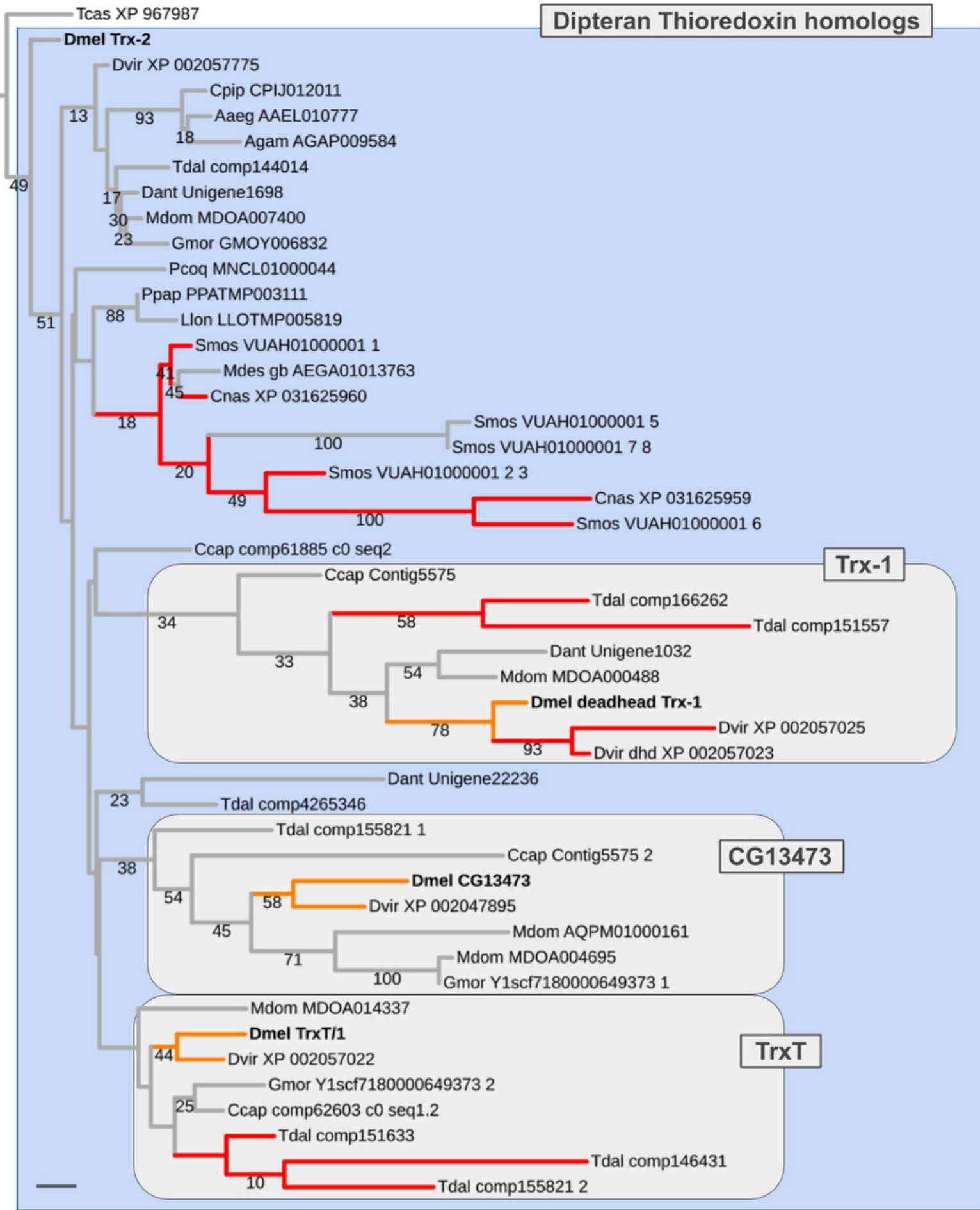




\section{Figure 7}

Dipteran Mdh2 gene family tree

Maximum likelihood tree of Mdh2 homologs compiled from dipteran species and select outgroup species. Numbers at branches represent branch support from non-parametric bootstrap analysis. Branch support values lower than $50 \%$ not shown. Orange branches indicate germline-specific paralogs in the Drosophila lineage. Blue branches lead to robber fly homologs. Species abbreviations as in Figure 4. Scale bar corresponds to 0.1 substitutions per site.

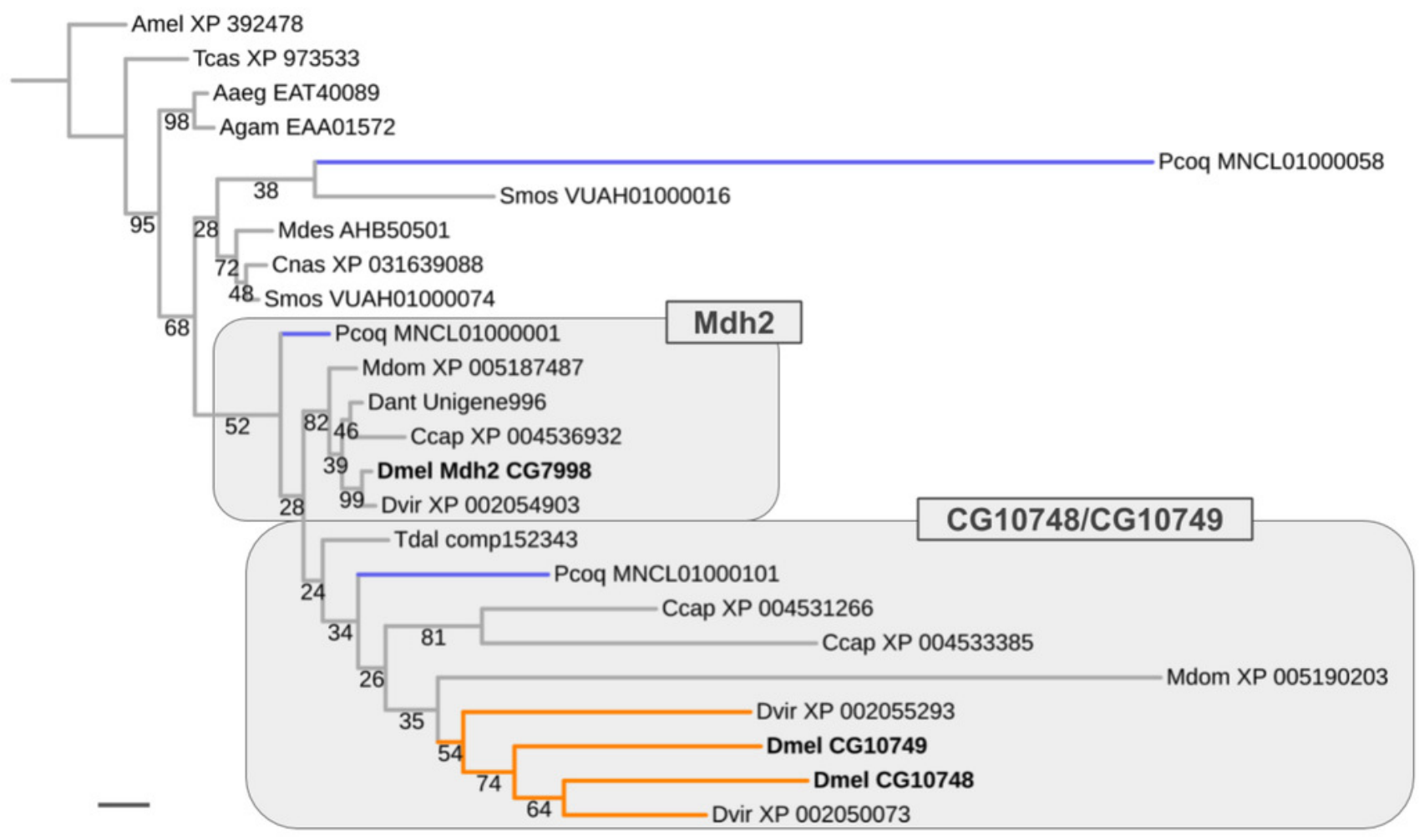




\section{Figure 8}

Dipteran Hexokinase gene family tree

Maximum likelihood tree of Hexokinase homologs compiled from dipteran and select outgroup species. Numbers at branches represent branch support from non-parametric bootstrap analysis. Branch support values lower than $50 \%$ not shown. Orange branches indicate germline-specific paralogs in the Drosophila lineage. Blue branches lead to robber fly homologs. Turquoise branches indicate gall midge (Bibionomorpha) homolog clusters. Species abbreviations same as in Figure 4 . Scale bar corresponds to 0.1 substitutions per site. 


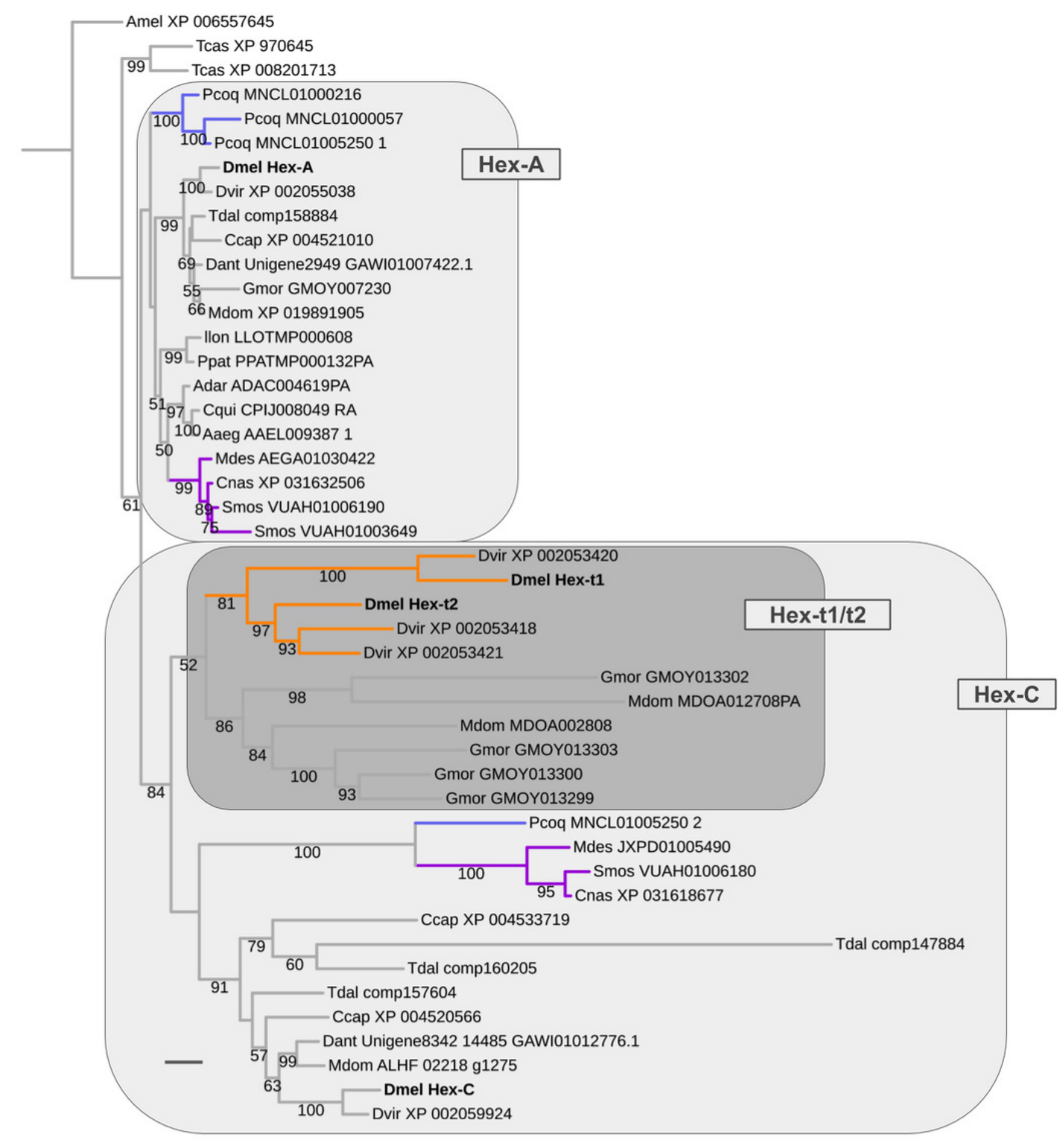




\section{Table $\mathbf{1}$ (on next page)}

Lineage-specific gene duplications in insect core gene families

Species name abbreviations as in Figure 1. Species-specific cell entries represent percentages of lineage-specific expanded gene families sorted by post-duplication size (2-6). Total percentages of lineage-specific expanded gene families given with absolute numbers and number of sampled gene families in parentheses. 


\begin{tabular}{|c|c|c|c|c|c|}
\hline $\begin{array}{c}\text { Gene family } \\
\text { sizes }\end{array}$ & Dmel & Agam & Tcas & Amel & Dmel / Others \\
\hline 2 & $7.9 \%(478)$ & $4.4 \%(246)$ & $4.9 \%(285)$ & $3.4 \%(185)$ & 1.9 \\
\hline 3 & $2.4 \%(144)$ & $0.8 \%(42)$ & $1.0 \%(59)$ & $0.5 \%(29)$ & 3.1 \\
\hline 4 & $0.9 \%(51)$ & $0.3 \%(19)$ & $0.3 \%(20)$ & $0.1 \%(6)$ & 3.2 \\
\hline 5 & $0.3 \%(18)$ & $0.1 \%(5)$ & $0.1 \%(10)$ & $0.0001 \%(2)$ & 3.0 \\
\hline 6 & $0.1 \%(7)$ & $0.1 \%(3)$ & $0.2 \%(12)$ & $0.02 \%(1)$ & 1.3 \\
\hline & $11.7 \%$ & $5.6 \%$ & $6.7 \%$ & $4.1 \%$ & \\
\hline Total & $(698 / 5,983)$ & $(315 / 5,581)$ & $(386 / 5,505)$ & $(223 / 5,448)$ & 2.1 \\
\hline
\end{tabular}




\section{Table 2 (on next page)}

Comparison of duplicate accumulation rates in developmental and energy metabolism gene families

Rates calculated as average numbers of duplications per gene family per million years. See

Figure 4 for branch definitions. Time intervals based on Wiegmann et al. (2011) and Obbard et al. (2012). 


\begin{tabular}{|l|c|c|c|}
\hline Branches & Energy & Development & Time (My) \\
\hline Drosophilidae LCA to present: & 0.0009 & 0.0007 & 30 \\
\hline $\begin{array}{l}\text { Drosophilidae+Calyptratae to Drosophilidae } \\
\text { LCA: }\end{array}$ & 0.0054 & 0.0011 & 35 \\
\hline Schizophora to Drosophilidae+Calyptratae LCA: & 0.0012 & 0.0021 & 15 \\
\hline Brachycera to Schizophora LCA: & 0.0003 & 0.0005 & 100 \\
\hline $\begin{array}{l}\text { Brachycera+Bibionomorpha -> Brachycera } \\
\text { LCA: }\end{array}$ & 0.0002 & 0.0004 & 50 \\
\hline Average: & 0.0016 & 0.001 & \\
\hline
\end{tabular}




\section{Table 3(on next page)}

Paralog expression specificities in the expanded energy metabolism gene families 


\begin{tabular}{|c|c|c|c|c|c|}
\hline Gene families & Members & $\begin{array}{c}\text { Cellular } \\
\text { localization }\end{array}$ & Testis biased & $\begin{array}{l}\text { Ovary } \\
\text { biased }\end{array}$ & Long branch \\
\hline \multirow[t]{2}{*}{ Glutaredoxin } & Grx1t & \multirow{2}{*}{ undefined } & 1 & & 0 \\
\hline & Grx1 & & digestive system & & 0 \\
\hline \multirow[t]{2}{*}{$\begin{array}{l}\text { Thioredoxin } \\
\text { reductase }\end{array}$} & Trxr-1 & $\begin{array}{c}\text { cytosol/mitochondria } \\
\text { । }\end{array}$ & $\begin{array}{c}\text { digestive } \\
\text { system/testis }\end{array}$ & & 0 \\
\hline & Trxr-2 & mitochondrial & 1 & & 1 \\
\hline \multirow[t]{4}{*}{ Thioredoxin } & Trx-2 & nuclear & 0 & & 0 \\
\hline & Trx-1 (dhd) & nuclear & 0 & 1 & 1 \\
\hline & TrxT/1 & chromosome & 1 & & 1 \\
\hline & CG13473 & - & 1 & & 1 \\
\hline \multirow{4}{*}{$\begin{array}{l}\text { Heat Shock } \\
\text { Protein } 60\end{array}$} & Hsp60 & \multirow{4}{*}{ cytosol/mitochondria } & \multicolumn{2}{|l|}{0} & 0 \\
\hline & Hsp60B & & \multicolumn{2}{|l|}{1} & 1 \\
\hline & Hsp60C & & \multirow{2}{*}{\multicolumn{2}{|c|}{0}} & 1 \\
\hline & Hsp60D & & & & 1 \\
\hline \multirow{3}{*}{$\begin{array}{l}\text { Mitochondrial } \\
\text { inner membrane } \\
\text { translocases }\end{array}$} & Tim13 & \multirow{3}{*}{ mitochondrial } & 1 & & 1 \\
\hline & CG34132 & & 0 & & 0 \\
\hline & CG42302 & & 1 & & 1 \\
\hline \multirow{4}{*}{$\begin{array}{l}\text { Mitochondrial } \\
\text { inner membrane } \\
\text { translocases }\end{array}$} & Tim17b1 & \multirow{4}{*}{ mitochondrial } & \multicolumn{2}{|l|}{1} & 1 \\
\hline & Tim17b2 & & \multicolumn{2}{|l|}{1} & 1 \\
\hline & CG1724 & & \multicolumn{2}{|l|}{1} & 1 \\
\hline & Tim17b & & \multicolumn{2}{|l|}{0} & 0 \\
\hline \multirow[t]{2}{*}{$\begin{array}{l}\text { P-P-bond- } \\
\text { hydrolysis-driven } \\
\text { protein } \\
\text { transmembrane } \\
\text { transporter } 20\end{array}$} & Tom20 & mitochondrial & 1 & 1 & 0 \\
\hline & tomboy20 & & 1 & 0 & 1 \\
\hline $\begin{array}{l}\text { P-P-bond- } \\
\text { hydrolysis-driven } \\
\text { protein } \\
\text { transmembrane } \\
\text { transporter } 40\end{array}$ & $\begin{array}{l}\text { Tom40 } \\
\text { tomboy40 }\end{array}$ & mitochondrial & 0 & 1 & 1 \\
\hline $\begin{array}{l}\text { Glycerol } 3 \\
\text { phosphate }\end{array}$ & Gpdh1 & cytosolic & muscle specific & & 0 \\
\hline
\end{tabular}




\begin{tabular}{|c|c|c|c|c|}
\hline \multirow[t]{2}{*}{ dehydrogenase } & Gpdh2 & & 1 & 1 \\
\hline & Gpdh3 & & 1 & 1 \\
\hline \multicolumn{3}{|c|}{ Glycerophosphate Gpo-1 } & \multicolumn{2}{|l|}{ muscle specific } \\
\hline 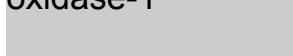 & Gpo-3 & \multirow[t]{2}{*}{ mitochondrial } & 1 & 1 \\
\hline & Gpo-2 & & 1 & 1 \\
\hline \multirow{3}{*}{$\begin{array}{l}\text { Mitochondrial } \\
\text { anion carrier } \\
\text { protein (MACP) } \\
\text { gene family }\end{array}$} & Ucp4A & \multirow{3}{*}{ mitochondrial } & 0 & 0 \\
\hline & Ucp4B & & 1 & 1 \\
\hline & Ucp4C & & 1 & 1 \\
\hline \multirow{2}{*}{$\begin{array}{l}\text { Mitochondrial } \\
\text { carrier (TC 2.A.29) } \\
\text { family }\end{array}$} & MME1 & \multirow[b]{2}{*}{ mitochondrial } & 1 & 1 \\
\hline & colt & & 0 & 0 \\
\hline \multirow{2}{*}{$\begin{array}{l}\text { Eukaryotic } \\
\text { mitochondrial } \\
\text { porin family }\end{array}$} & porin & \multirow{2}{*}{ mitochondrial } & 0 & 0 \\
\hline & Porin2 & & 1 & 1 \\
\hline \multirow[t]{4}{*}{ Hexokinase } & Hex-A & \multirow{4}{*}{ cytosolic } & 0 & 0 \\
\hline & Hex-C & & 0 & 1 \\
\hline & Hex-t1 & & 1 & 1 \\
\hline & Hex-t2 & & 1 & 1 \\
\hline \multirow{3}{*}{$\begin{array}{l}\text { Malate } \\
\text { dehydrogenase } 2\end{array}$} & Mdh2 & \multirow{3}{*}{ mitochondrial } & 0 & 0 \\
\hline & CG10748 & & 1 & 1 \\
\hline & CG10749 & & 1 & 1 \\
\hline \multirow[t]{2}{*}{$\begin{array}{l}\text { Succinate } \\
\text { dehydrogenase, } \\
\text { subunit C }\end{array}$} & SdhC & \multirow[t]{2}{*}{ mitochondrial } & 0 & 0 \\
\hline & CG6629 & & 1 & 1 \\
\hline \multirow[t]{3}{*}{$\begin{array}{l}\text { Malic enzyme like- } \\
1\end{array}$} & Menl-1 & \multirow{3}{*}{ mitochondrial } & 1 & 1 \\
\hline & Menl-2 & & 1 & 1 \\
\hline & Men-b & & 0 & 0 \\
\hline \multirow[t]{2}{*}{ Malic enzyme } & CG7848 & \multirow{2}{*}{$\begin{array}{c}\text { mitochondrial } \\
\text { mitochondrial/cytoso } \\
\text { । }\end{array}$} & 1 & 1 \\
\hline & Men & & 0 & 0 \\
\hline
\end{tabular}

